\title{
Lessons in the Design and Characterization Testing of the Semi-Span Super-Sonic Transport $\left(\mathbf{S}^{4} \mathbf{T}\right)$ Wind-Tunnel Model
}

\author{
James R. Florance, ${ }^{*}$ Robert C. Scott,${ }^{\dagger}$ Donald F. Keller, ${ }^{\ddagger}$ \\ Mark D. Sanetrik, ${ }^{*}$ and Walter A. Silva, ${ }^{\dagger}$ \\ NASA Langley Research Center, Hampton, Virginia, 23681
}

\begin{abstract}
This paper focuses on some of the more challenging design processes and characterization tests of the Semi-Span Super-Sonic Transport $\left(\mathbf{S}^{4} \mathbf{T}\right)$-Active Controls Testbed (ACT). The model was successfully tested in four entries in the National Aeronautics and Space Administration Langley Transonic Dynamics Tunnel to satisfy the goals and objectives of the Fundamental Aeronautics Program Supersonic Project Aero-Propulso-Servo-Elastic effort. Due to the complexity of the $\mathbf{S}^{4} \mathbf{T}$-ACT, only a small sample of the technical challenges for designing and characterizing the model will be presented. Specifically, the challenges encountered in designing the model include scaling the Technology Concept Airplane to model scale, designing the model fuselage, aileron actuator, and engine pylons. Characterization tests included full model ground vibration tests, wing stiffness measurements, geometry measurements, proof load testing, and measurement of fuselage static and dynamic properties.
\end{abstract}

\section{Introduction}

With the advent of the first generation of supersonic fighters, the feasibility of a supersonic transport (SST) appeared possible in the 1950s. By the early 1960s, the consortium of Aèrospatiale and the British Aircraft Corporation were given the go ahead to begin production of the Concorde. Concerns that the Concorde would eclipse all current long-range aircraft spurred the United States (U.S.) Congress to fund an SST design effort to develop more advanced, larger, faster, and longer ranged aircraft. However, environmental concerns were elevated in the late-1960s and the sonic boom and engine exhaust issues impacted lawmakers. Congress dropped funding for the SST

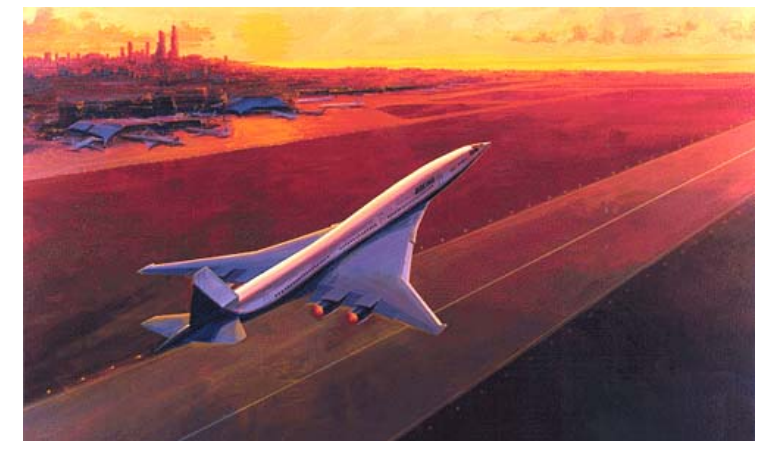

Figure 1. Artist concept of the Technology Concept Airplane. design efforts in 1971 and overland commercial supersonic flight was banned. ${ }^{1}$

In 1990, the National Aeronautics and Space Administration (NASA) and major U.S. aerospace companies teamed up to develop the next-generation supersonic passenger jet called the High Speed Civil Transport (HSCT). The HSCT would fly 300 passengers at more than 1,500 miles per hour and would cross the Pacific or Atlantic oceans in less than half the time of modern subsonic jets, and at a cost comparable to slower flights. NASA's High-Speed Research (HSR) program developed technologies to make the HSCT possible within 20-25 years. In December 1995, separate Boeing and McDonnell Douglas designs were merged to produce the Technology Concept Airplane (TCA) shown in an artist conceptual drawing in figure 1. The TCA was chosen as a single reference design concept aircraft and significantly narrowed technological development in the areas of propulsion and airframe structural components. ${ }^{2}$

*Aerospace Engineer, Aeroelasticity Branch, AIAA Senior Member.

†Senior Research Scientist, Aeroelasticity Branch, AIAA Associate Fellow.

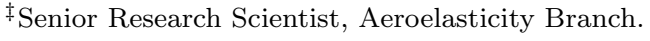


Many Task areas existed within the NASA HSR program. The Aeroelasticity Task was intended to provide demonstrated technology readiness to predict and improve flutter characteristics of an HSCT configuration. This required aerodynamic codes that were applicable to the wide range of flight regimes in which the HSCT would operate and were capable of providing the higher fidelity required for evaluation of aeroservoelastic coupling effects. Prediction of these characteristics would result in reduced airplane weight and risk associated with a highly flexible, low-aspect ratio supersonic airplane with narrow fuselage, relatively thin wings, and heavy engines. This Task was further subdivided into three subtasks. One subtask was to design, fabricate, and test wind-tunnel models that were suitable for providing an experimental database relevant to HSCT configurations. Within this subtask, a very sophisticated, aeroelastically-scaled semispan wind-tunnel model based on the TCA configuration was developed.

In fiscal year 1999, the HSR Program was phased out and the wind-tunnel model was not completed. ${ }^{3}$ Due to its high potential for valuable future research, development and fabrication of the model components were continued when funding and schedule allowed. This Field-of-Dreams strategy of "If you build it, they will come" ${ }^{4}$ paid off with the establishment of the NASA Fundamental Aeronautics Program (FAP) in May $2006 .^{5}$

One objective of the FAP was the development of system-level, multi-disciplinary capabilities for both civilian and military applications. Research performed in support of the FAP would yield design tools to benefit a broad range of vehicles in four categories: Subsonic Fixed Wing, Subsonic Rotary Wing, Supersonics, and Hypersonics. The principal objective of the Supersonics Project under the FAP was the development of multi-disciplinary, physics-based predictive design, analysis, and optimization capabilities for supersonic aircraft. The primary topics that were investigated under the Supersonics Project include: Sonic Boom Acceptability; Airport Noise Acceptability; High Temperature Durability; Acceptable High Altitude Emissions; Supersonic Cruise Efficiency; and Flight Dynamics, Stability, and Handling Qualities. Within the Flight Dynamics, Stability, and Handling Qualities topic, the investigation of Aero-Propulso-Servo-Elastic (APSE) phenomena was identified as a critical component to ensure safe and efficient supersonic flight.

The unique structural configuration of supersonic aircraft combined with nonlinear aerodynamics and rigid-body effects results in highly complex nonlinear aeroelastic/flight dynamics phenomena. These aeroelastic phenomena affect ride quality, gust loads, flutter, flight dynamics and control, and, possibly, engine performance. The aeroelastic/flight dynamics phenomena simultaneously influence the airframe and propulsion system controls, producing undesirable effects on performance and flying characteristics.

These APSE phenomena needed to be thoroughly understood in order for supersonic flight to be safe, comfortable, and efficient. In addition, there were opportunitities, through active controls, to exploit these phenomena for improved performance and efficiency. Analysis and design capabilities for slender supersonic aircraft may then be updated to include this new knowledge.

A vast body of analytical, computational, wind-tunnel and flight data exists on the aero-servo-elastic (ASE) systems for subsonic transport and supersonic fighter aircraft. ${ }^{6}$ Systems for control of undesirable aeroelastic phenomena, such as suppression of flutter, have been demonstrated many times. ${ }^{7,8,9}$ Systems that exploit vehicle flexibility for improved performance, such as vehicle roll control beyond aileron reversal and wing load alleviation have also been demonstrated. ${ }^{10,11}$

Considerably less data are available for supersonic transport configurations. Under the auspices of the HSR program, research was performed in the areas of computational and experimental aeroelasticity, and aeroelastic wind-tunnel models were designed, built, and tested in the NASA Langley Transonic Dynamics Tunnel (TDT). ${ }^{12}$ Within the Supersonics Project under the FAP, the aeroelastically-scaled semispan windtunnel model, referred to as the SemiSpan SuperSonic Transport $\left(\mathrm{S}^{4} \mathrm{~T}\right)$ Active Controls Testbed (ACT), was completed and tested in the TDT. Equipped with three active surfaces (ride control vane (RCV), aileron, horizontal tail) and flow-through nacelles with flexible mounts, and having been designed to flutter within the TDT operating boundary, it proved to be a valuable testbed for investigating ASE issues associated with supersonic cruise configurations. ${ }^{13}$

The model was installed and tested in four separate TDT entries to determine passive and active controls characteristics of the model and to demonstrate on a supersonic transport configuration the ability to reduce gust loads, improve ride quality, and suppress flutter through active controls. ${ }^{14,15,16,17}$ As a guide to the reader, figure 2 gives a representation of the events leading to the design and testing of the $\mathrm{S}^{4} \mathrm{~T}-\mathrm{ACT}$. The development of this model, with particular focus on the lessons learned during the design and testing process, are the focus of this paper. 


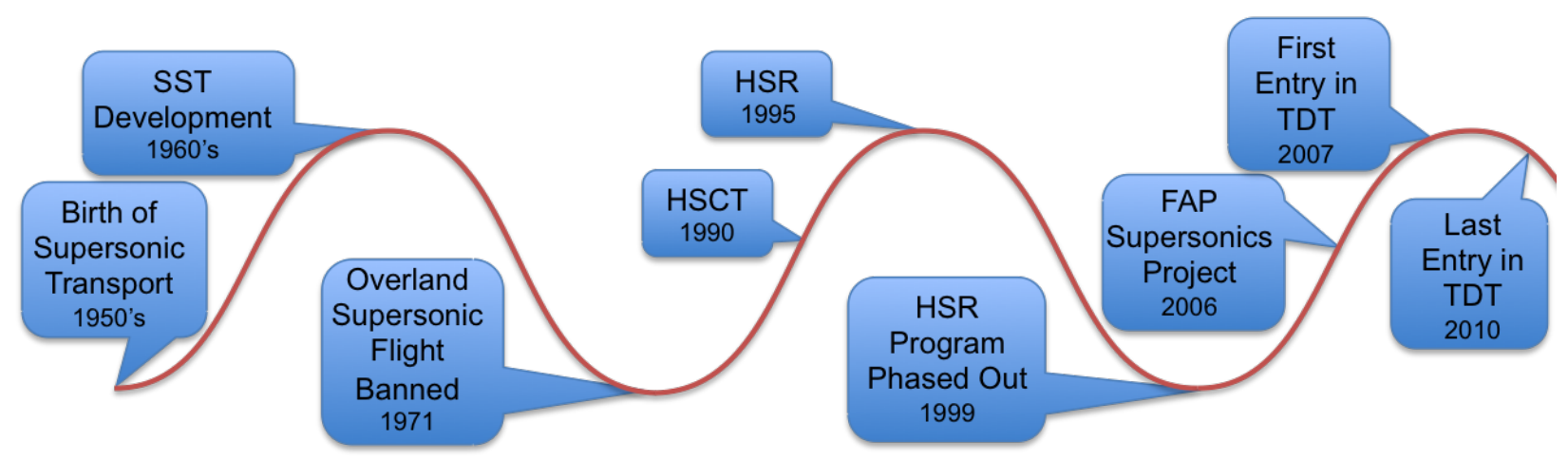

Figure 2. Supersonic passenger-transport aeroelastic research through the years.

\section{Model Description}

The $\mathrm{S}^{4} \mathrm{~T}-\mathrm{ACT}$ is a very sophisticated aeroelastic semispan wind-tunnel model designed and fabricated at NASA Langley Research Center (LaRC). The wind-tunnel model is 16.5 feet in length with a model span of 3.25 feet. The model is shown in figure 3 in two different states of assembly while mounted on a backstop in a TDT model preparation area. Figure 3(a) contains a photo of the model fully assembled as it would be tested in the tunnel and figure 3(b) contains a photo of the model with the fuselage fairing removed and with key features highlighted. Those features are the three active surfaces (RCV, aileron, horizontal tail), flow-through nacelles with flexible attachments, and the flexible fuselage beam attached to a rigid beam through spring flexures referred to from here on as nodal mounts. The engine nacelles include provisions for varying their masses and mount stiffnesses, allowing researchers to vary the test conditions at which flutter occurs. The wing root and tip chords are 82 inches and 6 inches, respectively. The wing attaches to the flexible fuselage beam at four locations through shear pins on the lower and upper surfaces of the wing. The wing main spar is located between the aft two attachment points and runs out span wise to the wing tip.

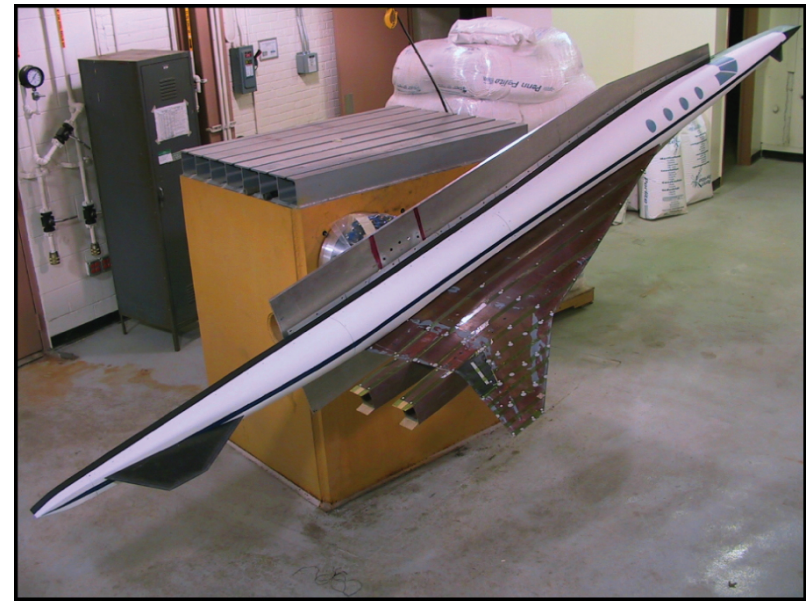

(a) Model fully assembled with nonmetric backplate and fuselage fairing.

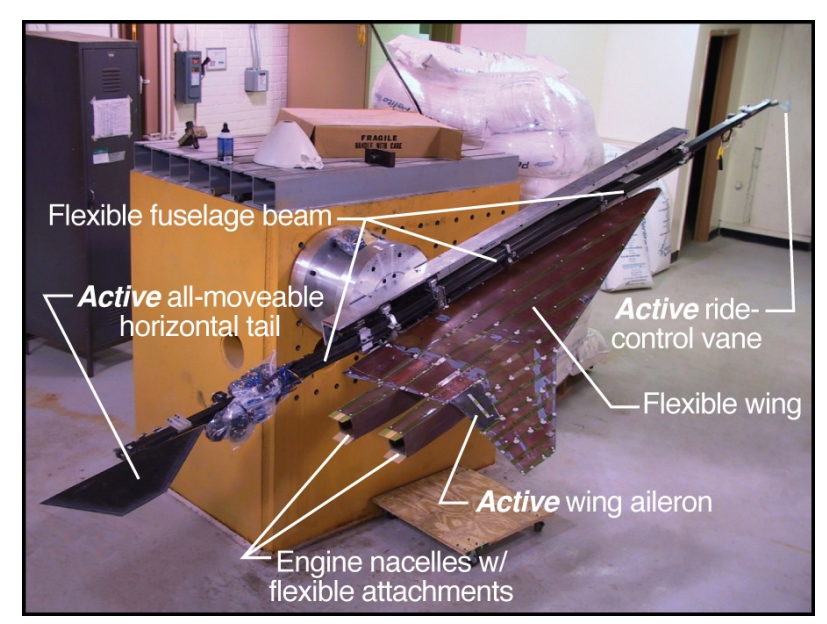

(b) Model without fuselage fairing installed.

Figure 3. Photographs of $\mathrm{S}^{4} \mathrm{~T}-\mathrm{ACT}$ mounted on backstop.

The non-metric (i.e. aerodynamic loads not measured by the balance) fuselage fairing consists of a graphite/epoxy shell mounted to an aluminum back plate. The fairing assembly can be easily seen by comparing the photos in figure 3 and noting the parts removed. The fairing is supported by an aluminum spool that bridges the balance and attaches the fuselage fairing to the TDT sidewall turntable directly. A gap is left between the wing and fuselage fairing so the loads on the fairing are not transmitted to the balance. The non-metric fuselage fairing eased the design of the flexible fuselage beam attachment to the balance and provided the volume for housing the flexible mounts, control surface actuators, and instrumentation hardware. 
The instrumentation in the wing, illustrated in figure 4, is extensive. The wing is populated with 26 accelerometers, the engines with four each, and the fuselage with four. In addition, there are 93 unsteady pressure transducers on the wing (53 on the upper surface and 40 on the lower surface) arranged in six chord wise rows, 12 strain gages (bending and torsion gages at three locations on the upper and lower surface), and additional torsional strain gages that measure ride-control-vane, aileron, and horizontal-tail positions. The flexible fuselage beam is instrumented with four accelerometers. The three servo-valves (one for each control surface actuator) were mounted on the flexible fuselage. A Q-flex sensor was used to measure angle of attack. A 5-component sidewall balance (TDT-05S) was used to measure loads on only those components of the model connected to the rigid fuselage beam (RCV, wing, and horizontal tail). Figure 5 contains the distribution of the wing pressure transducers with the left side of the figure corresponding to the upper surface and the right side of the figure corresponding to the lower surface. Volume constraints precluded the placement of pressure transducers and accelerometers at the leading and trailing edges of the outboard wing section.



Figure 4. Model Instrumentation layout.

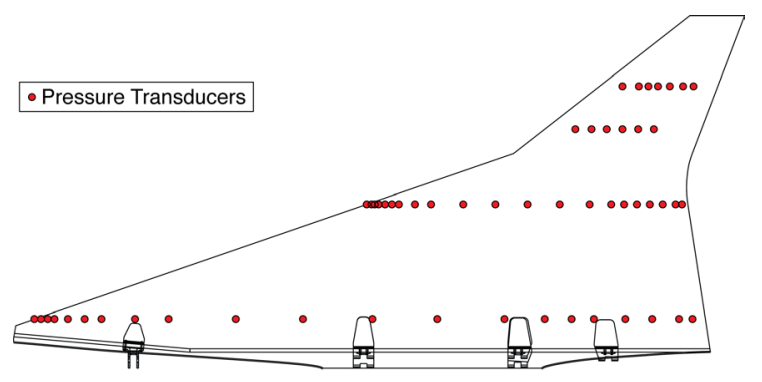

(a) Upper surface.

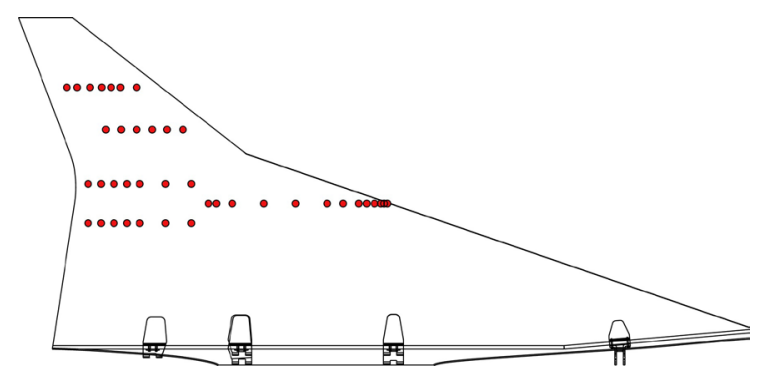

(b) Lower surface.

Figure 5. Wing unsteady pressure transducer locations.

\section{Design}

Aeroelastic model designs vary with the objectives of the program, which presents unique challenges in their design and testing. Typically, aeroelastic models can be classified by their configuration and construction. Component models, semispan models, or models of the complete vehicle are the most common configurations. Within these configurations, model construction types are categorized as beam/spar/pod models, plate models, stressed skin models, or replica models. The configuration and construction type is driven by the specific test objectives, with simple beam/spar/pod and plate models used for trade studies or focused component research and more complicated beam/spar/pod and stressed skin/replica models used for flutter clearance or full vehicle models. A detailed description of the configurations and construction types can be found in reference 18 . 
The process of designing an aeroelastic model from a vehicle or component concept can also vary significantly with each new model. Vehicle or component properties can be extracted from the full-scale vehicle and then scaled to begin the design of the model or the full-scale vehicle can be scaled and the properties extracted from the scaled model. The choice is often driven by complexity of the program objectives and type of data required to satisfy those objectives. Once the scaled properties are determined, the process of creating physical model parts from the scaled properties will vary depending on the model construction type. The process for designing and fabricating the $\mathrm{S}^{4} \mathrm{~T}$-ACT followed the path of a stressed skin semispan model for the wing and a beam/spar/pod model for the fuselage, with the control surfaces being inertia scaled but not stiffness scaled. The full-scale vehicle was aeroelastically scaled to model scale and the properties extracted to design the model.

In order to design a model with the goals of accurately simulating the engine-fuselage coupling flutter mechanism of the TCA and demonstrating active flutter suppression, the data detailing the TCA structural and dynamic characteristics were compiled. This provided a baseline for the design of the model, even as the TCA design continued to evolve, and included the TCA geometry, structural arrangement, structural properties, weight and inertia properties, instrumentation, and any special items required for testing.

Once the design goals were fixed, the process of designing the model began with extracting the structural and dynamic characteristics from the TCA finite element model (FEM), shown in figure 6. In this FEM, there was no RCV modeled and the engines were represented by a cruciform structure simulating the engine mass and inertia distribution. Both items were created from geometry data. There were many challenging issues in creating the physical wind-tunnel model from the information in the TCA FEM. This section of the paper will focus on these challenges, particularly the scaling and design of the outboard wing, the creation of an equivalent stiffness beam for the TCA fuselage, the development of the aileron actuator, and the determination of the engine mass variations and pylon stiffness distribution.

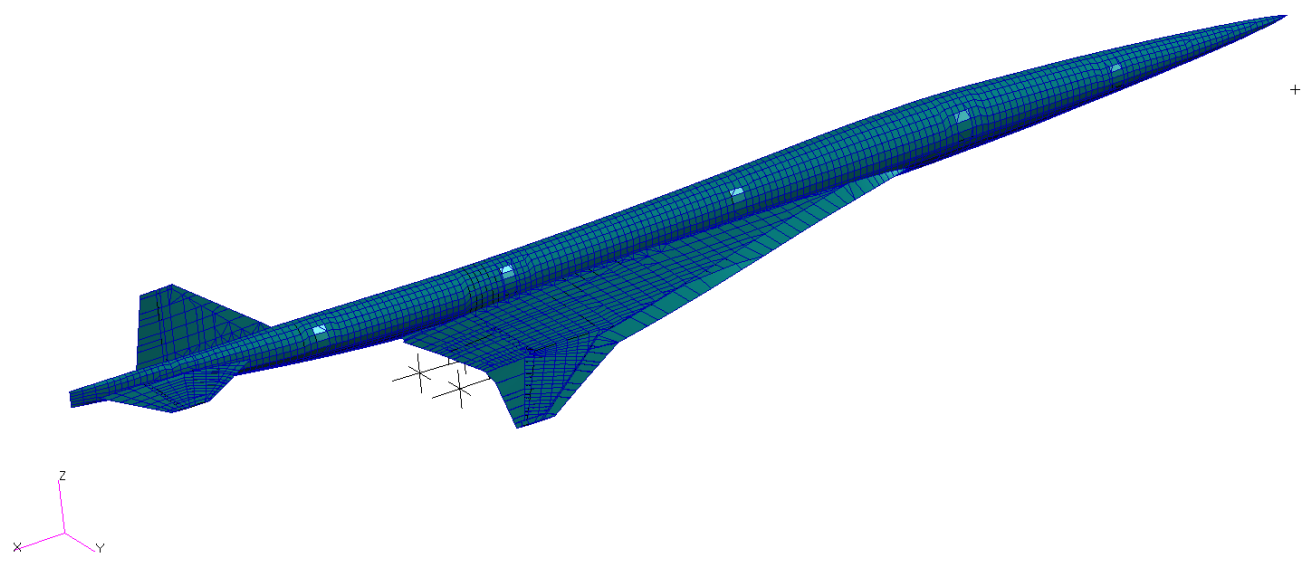

Figure 6. Finite element model of the TCA.

\section{III.A. Aeroelastic Scaling}

This section will discuss the aeroelastic scaling of the full-size TCA to model-scale. Since large models are easiest to construct, the geometric scale factor was established to maximize the model size suitable for the TDT. The length of the TDT test section constrained the model fuselage length to 16 feet, which yielded a model length scale factor of just under $5 \%$, based on the 326 -foot length of the TCA. The flutter-critical flight condition to be scaled was the TCA with a gross weight of 700,000 pounds, at a cruise speed of Mach 0.95, an altitude of roughly 22,500 feet, and a dynamic pressure $\left(q_{A}\right)$ of 540 pounds per square foot (psf). The model test condition in the tunnel was chosen such that the model dynamic response and instrumentation response were sufficient to obtain quality data without applying large aerodynamic loads that would overly constrain the design and fabrication of the model. The condition chosen matched the TCA flight condition Mach number using a heavy gas test medium and reduced the $q_{M}$ to $150 \mathrm{psf}$. With these geometric and flight parameters for the TCA and the design condition in the tunnel, scale factors were determined from the equations in Table 1 that yielded a model with aeroelastic characteristics scalable to the full-sized TCA. The values for the scale factors used to design the model are provided in the last column of Table 1. Also, $a_{M}$ and $a_{A}$ are the speed of sound at model and aircraft scales (respectively) and the reduced frequency, $k=\frac{\omega \cdot L}{V_{\infty}}$. 
Table 1. TCA to model scale factors

\begin{tabular}{l|lcl}
\hline Scale Factor (SF) & Equation & Symbol & Value \\
\hline Dynamic Pressure & $q_{S F}=q_{M} / q_{A}$ & $q_{S F}$ & 0.2778 \\
Velocity & $V_{S F}=a_{M} / a_{A}$ & $V_{S F}$ & 0.5341 \\
Density & $\rho_{S F}=q_{S F} / V_{S F}$ & $\rho_{S F}$ & 0.9737 \\
Length & $L_{S F}=L_{M} / L_{A}$ & $L_{S F}$ & 0.0491 \\
Mass & $M_{S F}=\rho_{S F} \cdot L_{S F}{ }^{2}$ & $M_{S F}$ & $1.1512 \times 10^{-4}$ \\
Thickness & $t_{S F}=L_{S F} \cdot q_{S F}$ & $t_{S F}$ & 0.0136 \\
Area & $a_{S F}=L_{S F}{ }^{2} \cdot q_{S F}$ & $a_{S F}$ & $6.6912 \times 10^{-4}$ \\
Time & $T_{S F}=L_{S F} / V_{S F}$ & $T_{S F}$ & 0.0919 \\
Force & $F_{S F}=M_{S F} \cdot L_{S F} / T_{S F}{ }^{2}$ & $F_{S F}$ & $6.6912 \times 10^{-4}$ \\
Rigid Body Acceleration & $A_{S F}=L_{S F} / T_{S F}$ & $A_{S F}$ & 5.813 \\
Reduced Frequency Ratio & $c=k_{A} / k_{M}$ & $c$ & 1.0 \\
Frequency & $\omega_{S F}=(1 / c) \cdot\left(V_{S F} / L_{S F}\right)$ & $\omega_{S F}$ & 10.88 \\
Time' & $T P_{S F}=c \cdot T_{S F}$ & $T P_{S F}$ & 0.0919 \\
Bending stiffness & $E I_{S F}=M_{S F} \cdot L_{S F}{ }^{3} / T P_{S F}{ }^{2}$ & $E I_{S F}$ & $1.6118 \times 10^{-6}$ \\
Torsion stiffness & $G J_{S F}=E I_{S F}$ & $G J_{S F}$ & $1.6118 \times 10^{-6}$ \\
Rotational stiffness & $K_{A}=M_{S F} \cdot L_{S F}{ }^{2} / T P_{S F}{ }^{2}$ & $K_{A}$ & $3.2840 \times 10^{-5}$ \\
\hline
\end{tabular}

\section{III.B. FEM Scaling}

Once the scale factors were determined, the vehicle components were then scaled so that model design could be initiated. Starting with the FEM of the TCA, a scaling algorithm was developed to size the various components of the TCA. The algorithm for scaling the full-size TCA Nastran FEM to a model-scale Nastran FEM involved scaling the structural stiffness of the TCA components, mass scaling the non-structural mass elements, and finally scaling the moments of inertia and spring rates. The grid point coordinates were scaled by the length scale factor, $L_{S F}$. The skins and shear webs (i.e. plate element properties) were scaled by the thickness scale factor, $t_{S F}$. This process assumed there were no material substitutions from full-scale TCA at this point. Also, the cores for multiple facesheet skins (i.e. composite elements) were scaled by the length scale factor, $L_{S F}$, and the vertical locations of all the skin elements were adjusted to half the wing thickness to properly locate them with respect to the grid points. The spar and rib caps (i.e. beam element properties) were scaled by the area scale factor, $a_{S F}$. The process of scaling the beam element properties ignored the self inertia of the caps and there was no material substitution. At this point, unit static loads in bending and torsion were applied on both full-scale and model FEM to compare stiffness results using the bending stiffness scale factor, $E I_{S F}$. This concluded the structural scaling of the full-scale TCA, leaving the mass properties to be scaled.

To scale the system mass of the model (i.e. concentrated mass elements and the non-structural mass on the element properties) the mass scale factor, $M_{S F}$, was divided by the appropriate length or area scale factor $\left(L_{S F}\right.$ or $\left.a_{S F}\right)$ to obtain mass per unit length or area and applied to the corresponding one or two dimensional element. The mass for the skins, shear webs, and caps, were scaled by adjusting the density on the material properties for these elements since the mass scale factor uses the $L_{S F}{ }^{3}$ for volume, and the skins and webs use $L_{S F}{ }^{2} \cdot t_{S F}$ and the caps use $L_{S F} \cdot a_{S F}$. Therefore the skin and web densities were scaled by $\frac{M_{S F}}{L_{S F^{2}} \cdot t_{S F} \cdot \rho_{S F}}$, and the cap densities by $\frac{M_{S F}}{L_{S F} \cdot a_{S F} \cdot \rho_{S F}}$. Note that the core volume is correct because it was changed by $L_{S F}{ }^{3}$, however the density needed to be adjusted by the density scale factor, $\rho_{S F}$.

Finally, the remaining element properties (i.e. one-dimensional bar element area moments of inertia, elastic spring rates, two-dimensional plate element bending moment of inertia ratio, etc.) are scaled by their appropriate scale factor. The area moments of inertia scale by the bending stiffness scale factor, $E I_{S F}$, the actuator springs scale by the rotational stiffness scale factor, $K_{A}$, and the bending moment of inertia ratio is defined as $\frac{12 I}{t^{3}}$, and scales by, $\frac{E I_{S F}}{t_{S F^{3}}}$.

This resulted in a replica model-scale FEM of the full-scale TCA FEM. Normal modes analysis were conducted and the frequency results were compared using the frequency scale factor, $\omega_{S F}$. The total mass 


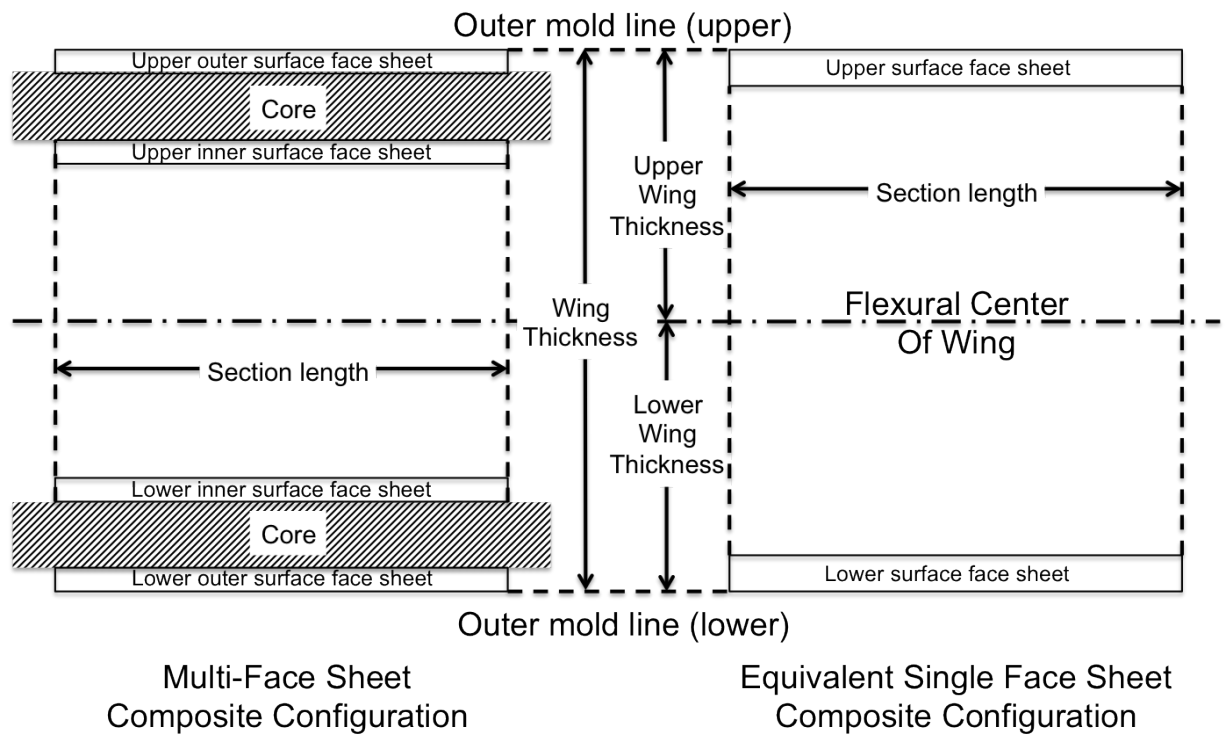

Figure 7. Graphical representation of multiple facesheet skins converted to single facesheet laminate.

was checked to verify it was scaled by the mass scale factor, $M_{S F}$. The scaling effort from the full-scale TCA to a model-scale TCA resulted in an exact match of the modal frequencies and mass, however the analytical model still needed to be modified to create a buildable physical model. The final step in scaling the full-scale TCA FEM to a buildable model-scale FEM was to convert the multiple facesheet skins to a single facesheet laminate, shown graphically in figure 7, convert the TCA fuselage to an equivalent aeroelastic beam, and develop an appropriate mounting system. Table 2 presents the frequency results of the TCA scaling and the conversion of the analytical model to a buildable model. The designed buildable model frequencies were roughly $5 \%$ higher than the scaled TCA frequencies, meaning the designed model was slightly stiffer or lighter than the scaled TCA.

Table 2. Comparison of TCA FEM and designed FEM modal frequencies

\begin{tabular}{ccccc}
\hline Mode & Full-scale TCA, Hz & Model-scale TCA, Hz & Designed Model, $\mathrm{Hz}$ & \% Difference \\
\hline 1 & 1.12 & 12.19 & 12.81 & 4.84 \\
2 & 1.33 & 14.42 & 15.06 & 4.25 \\
3 & 1.79 & 19.44 & 20.81 & 6.58 \\
4 & 1.92 & 20.93 & 21.66 & 3.37 \\
5 & 2.45 & 26.68 & 27.95 & 4.54 \\
6 & 2.56 & 27.82 & 29.22 & 4.79 \\
\hline
\end{tabular}

\section{III.C. Wing}

The design of the outboard wing skins of the wind-tunnel model was a challenging task due to the thinness of the full-scale laminates used in the TCA skins. One method for scaling full-scale, composite laminate structures is to develop ply number, ply thickness and laminate modulus scale factors (a.k.a. laminate replica method). These scale factors are applied to the full-scale laminates to create a model laminate with realistic ply orientations and cover area ratios. By maintaining ply direction ratios and orientation along with scaled modulus, the important model laminate stiffness properties will match the full-scale laminate stiffness properties. However, when dealing with thin full-scale laminates, it is difficult to achieve the fidelity required in a typical aeroelastic model without some modifications to this method.

The ideal scaled laminate skin would have an integer number of model plies (while maintaining fullscale ply orientation ratios), whose total thickness would scale as the length scale factor. This is rarely accomplished when scaling practicalities such as matrix/filament contributions and tunnel design points affecting the dynamic pressure ratio are taken into account. Compromises on the ideal are often achieved 
by one or more of the following techniques: 1) material substitution, 2) laminate configuration changes, 3) smearing of spar, rib and local stiffener cap areas into the wing skin, 4) changing the airfoil thickness to chord ratio, and last and least desirable, 5) altering the reduced frequency ratio, $c=\frac{k_{A}}{k_{M}}$. The last factor affects the relationship of angle-of-attack due to vibration velocity and angles due to vibration amplitudes (twist or bending slope and/or control surface rotation). Wasserman and others have shown that careful consideration must be taken before conducting investigations of all but classic bending/torsion flutter mechanisms when this ratio is altered. ${ }^{19}$ As shown in Table 1 , the reduced frequency ratio is unity for the $\mathrm{S}^{4} \mathrm{~T}$ model.

In order to simplify construction and model analysis, the TCA full-scale, double-faced laminates used for the upper and lower surface wing skins were converted to stiffness-equivalent, single-face laminates. The initial scaling results indicated that a very thin (0.001-inch thick), uni-directional, pre-preg, fiberglass/epoxy (reduced modulus) tape or an extremely thin (0.0005-inch thick), uni-directional, graphite/epoxy tape would be required to simulate the 0.0052-inch graphite/epoxy laminate in the TCA tip without compromising the outer contour. Some compromise on wing skin thickness requirements in very thin model laminate areas may be obtained by the inclusion (smearing) of spar and rib cap areas into the model skin laminate. Due to each ply having a specific thickness, the construction of the model skin laminate also required that the number of plies be an integer and the direction of the plies match from region to region to allow for the largest continuous ply during stacking (see figure 8). Matching the scaled weight of the outboard wing resulted in the initial selection of extremely thin graphite/epoxy tape as the material for fabricating the the wing. This proved to be a poor material choice due to the lack of strength in the very thin laminate skins.

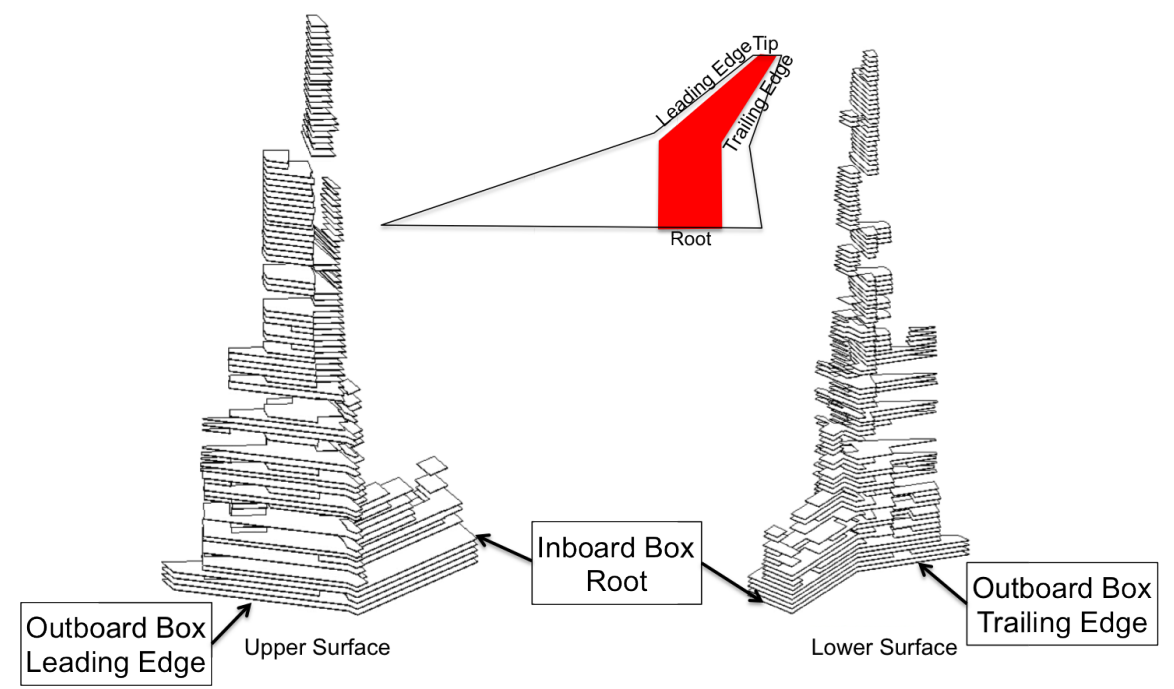

Figure 8. Upper and lower skin ply stacking for the inboard and outboard wing box.

In terms of stiffness, a fiberglass skin is roughly three to four times thicker than a comparable graphite skin. This would have two important benefits for the model. First, the model would be much stronger due to increased skin thickness and more resistant to skin buckling. This was demonstrated by failing a minimum gage (4 layers of 0.00075-inch tape) graphite beam and a minimum gage fiberglass beam (8 layers of 0.0017 inch tape). The beams were similar in stiffness, but the graphite beam failed at a load of 13 pounds, while the fiberglass held a 50 pound load without failing. This represented at least a factor of four increase in load carrying capability. Second, the thicker skins would be more durable. Experience with preparing and testing flutter models suggested that this lack of durability in the graphite skins would be a significant issue. Good correlation between the analytical and experimental results for quantifying the fiberglass/epoxy material properties and poor correlation for the graphite/epoxy material properties provided further confidence in the fiberglass/epoxy material selection. Thus, the design was modified to use the fiberglass/epoxy material for the skins.

\section{III.D. Fuselage}

The fuselage consists of a graphite/epoxy flexible beam (Figure 9) attached to an aluminum c-channel "rigid" beam and surrounded by a fiberglass-over-honeycomb fairing. The graphite/epoxy beam was developed by 
determining the bending and torsional stiffness of the thin-shelled TCA fuselage structure and designing a beam with the appropriate bending stiffness. Flanges were added along the flexural center of the beam to match the torsional stiffness and minimally impact the bending stiffness. Due to the TCA's thin-shelled structural fuselage arrangement, the bending due to end shear is not negligible and Timoshenko beam theory ${ }^{20}$ was used to match bending deflections between the full scale vehicle and model. Ballast mass was added to the beam to match the running weight of the scaled TCA fuselage. The "rigid" c-channel beam attachment mechanisms provided the flexible beam pitch and vertical degrees of freedom (along with minimal fore-aft motion) but constrained roll, yaw, and side motion. The two nodal mounts provided vertical stiffness through four U-springs (two springs per mount). These nodal mounts can be locked with expansion spacers placed between the stop spacers on the U-springs for testing if a nearly cantilevered boundary condition is desired. Figure 10 shows the how well the model-scale TCA fuselage stiffness and vertical bending deflections compared with the designed model fuselage beam.

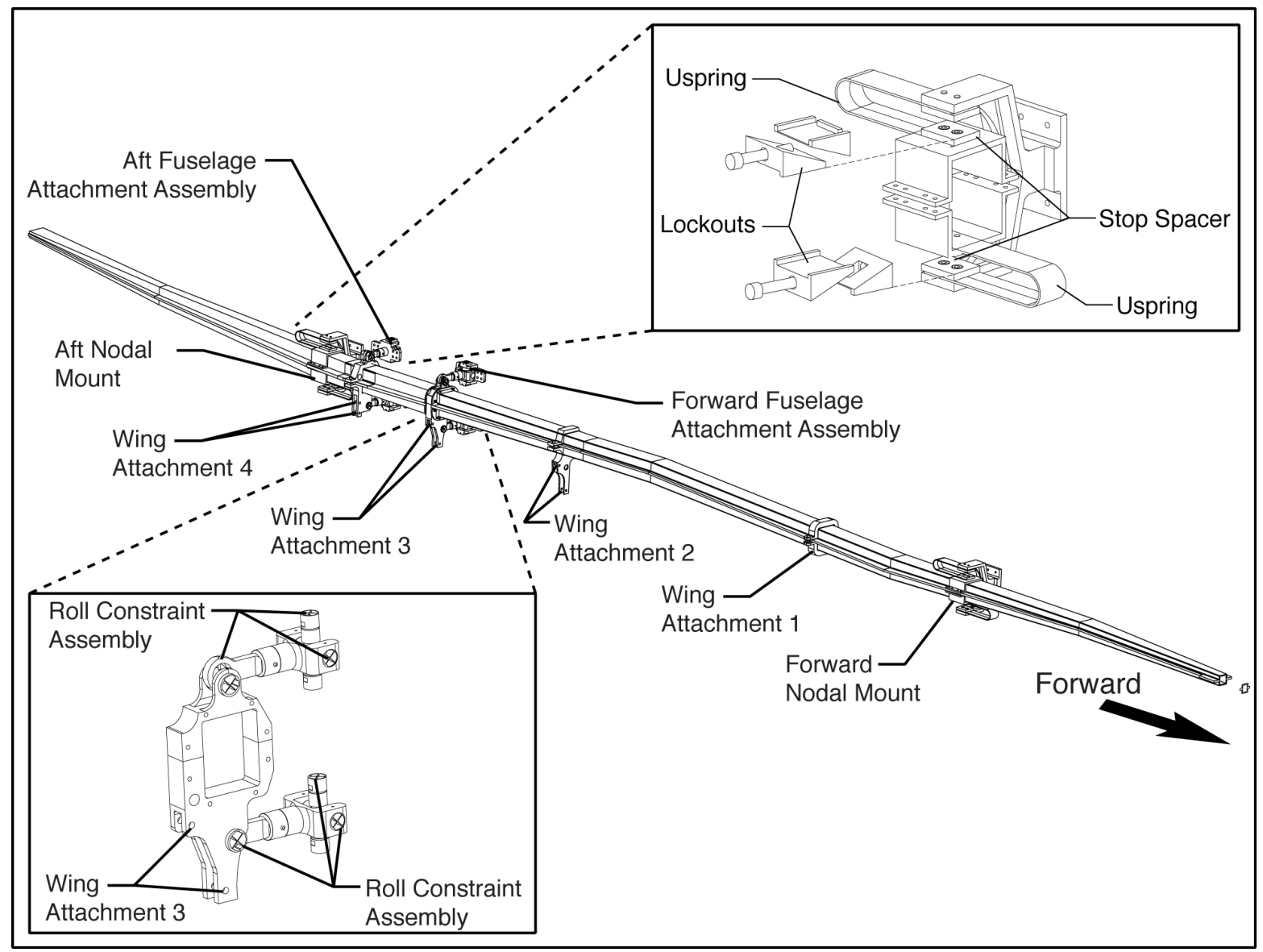

Figure 9. Fuselage beam showing attachment points and nodal mounts.

In order to minimize the impact of the tunnel mounting system on the fuselage modal characteristics, several sophisticated mounting mechanisms were required to hold the model to the tunnel sidewall. Roll and side constraint mechanisms would constrain the fuselage in roll, yaw, and lateral degrees of freedom, but allow for normal, axial, and pitch degrees of freedom which were of interest. Allowing the normal and pitch degrees to be the least impacted was the highest priority, with a great desire to constrain the axial degree of freedom. These constraint mechanisms consisted of bearings mounted vertically and horizontally as pointed out in the Roll Constraint Assembly in the lower left corner of figure 9. Mechanisms referred to as nodal mounts employed large U-springs that were designed to have very little pitch stiffness and a large axial stiffness. The normal stiffness was set to hold the flexible fuselage beam centered during testing and minimizing their impact on the fuselage pitch modes by locating them at the node locations for the second bending mode of the beam. Figure 9 highlights these mounting mechanisms. In order to conduct certain characterization tests such as wing and fuselage stiffness and ground vibration testing in a cantilevered configuration, lockout devices were designed to restrict motion at the nodal mounts. The design of these 


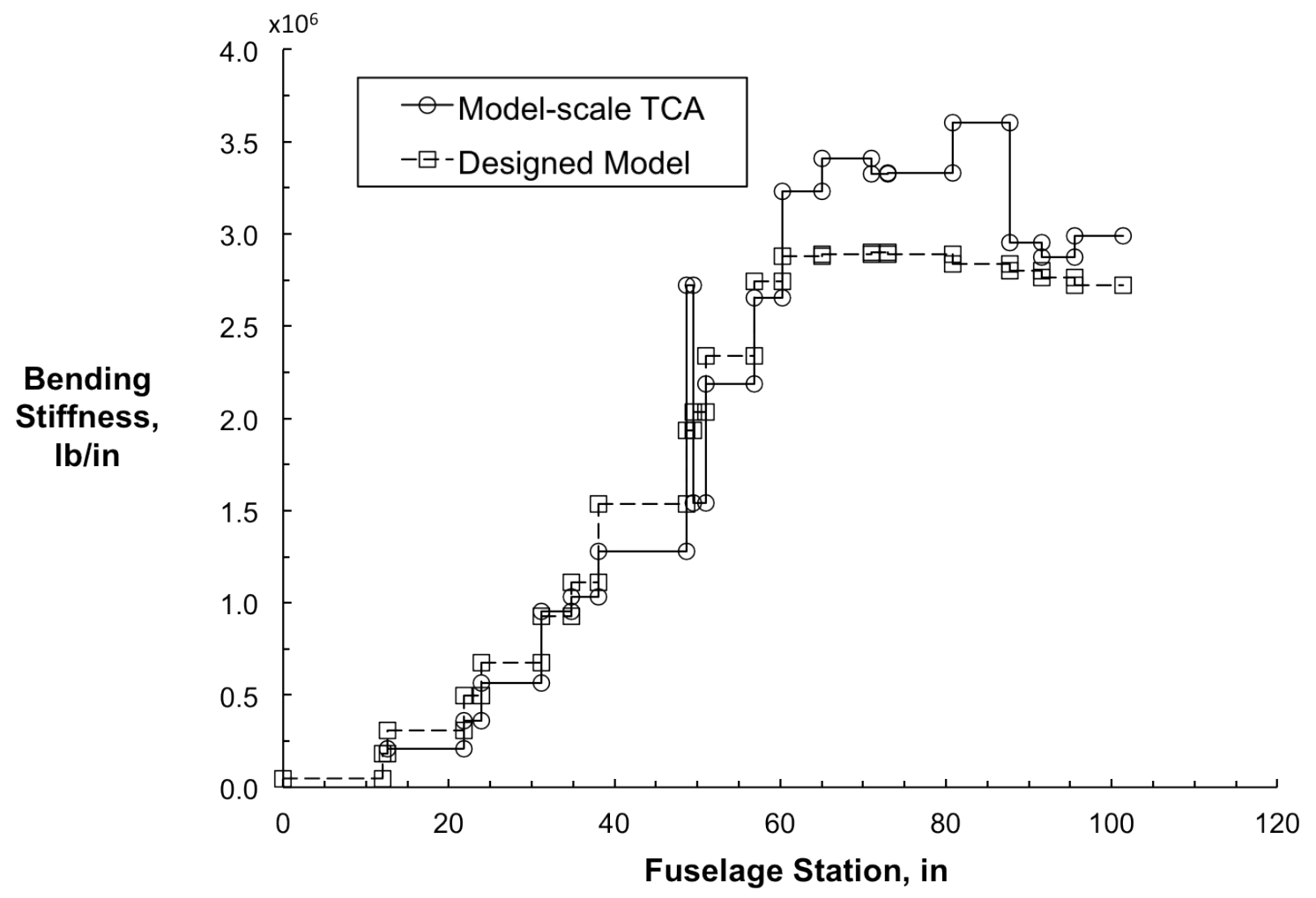

(a) Scaled fuselage stiffness.

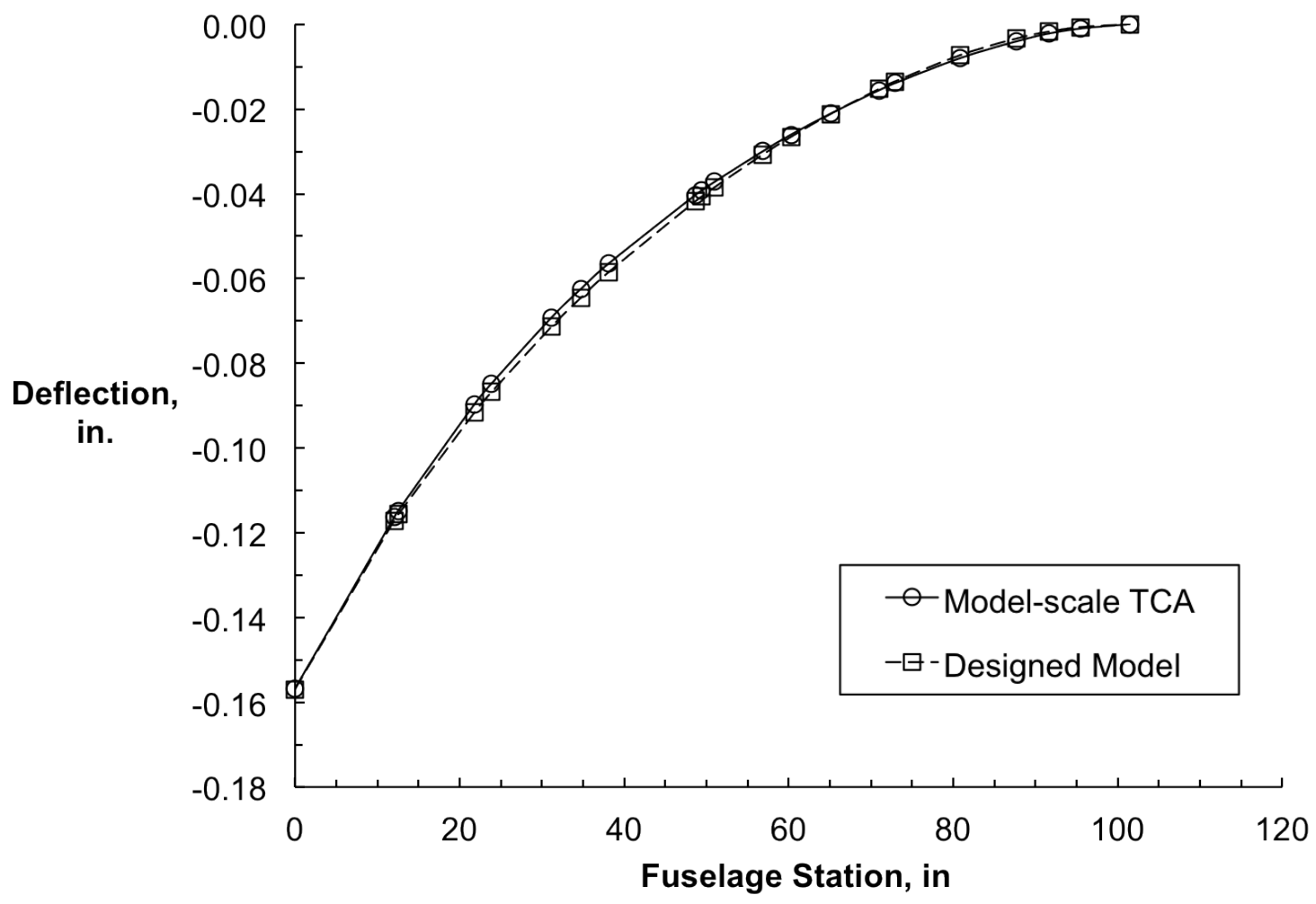

(b) Scaled fuselage bending deflections.

Figure 10. Fuselage stiffness and vertical bending deflections for the model-scale TCA FEM and designed model FEM. 
expanding wedge-shaped lockouts is presented in the upper right corner of figure 9. These lockouts were placed between the upper and lower stop spacers and a screw pulled the wedges over each other to expand the lockouts and fill the gap between the U-spring ends.

\section{III.E. Actuators}

In choosing the type and size of the actuators for the three control surfaces, considerations were paid to the power, responsiveness, weight, and volume constraints for each required location. The volume constraints of the actuators for the RCV and horizontal tail were the least challenging due to their location inside the fuselage fairing. The weight needed to be kept reasonably low, but the driving factors were the power and responsiveness of the actuators. Piston-type actuators were chosen that were available from merchandise stock with little customization required. The actuators chosen had a \pm 1 -inch stroke and 0.5 -inch bore. The actuator assemblies for these surfaces are shown in figure 11(a).

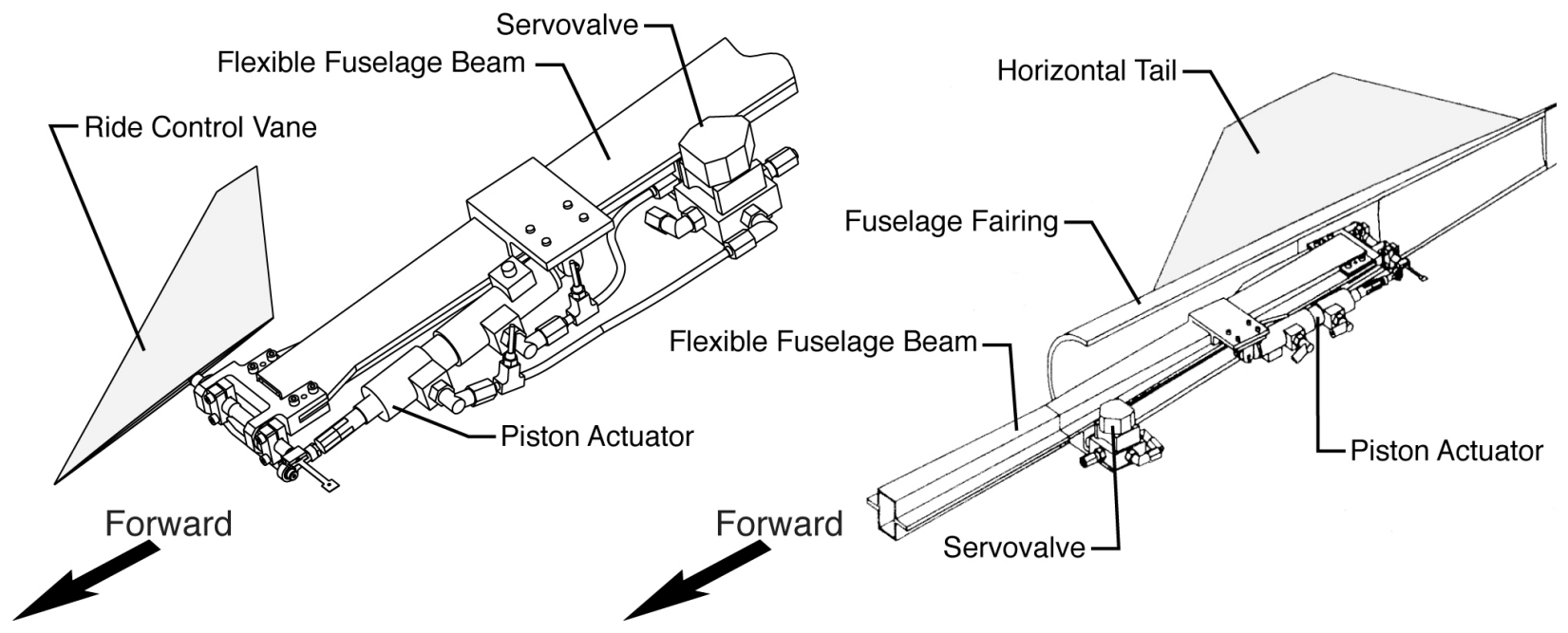

(a) Drawings of the RCV (left) and horizontal tail (right) actuator assemblies.

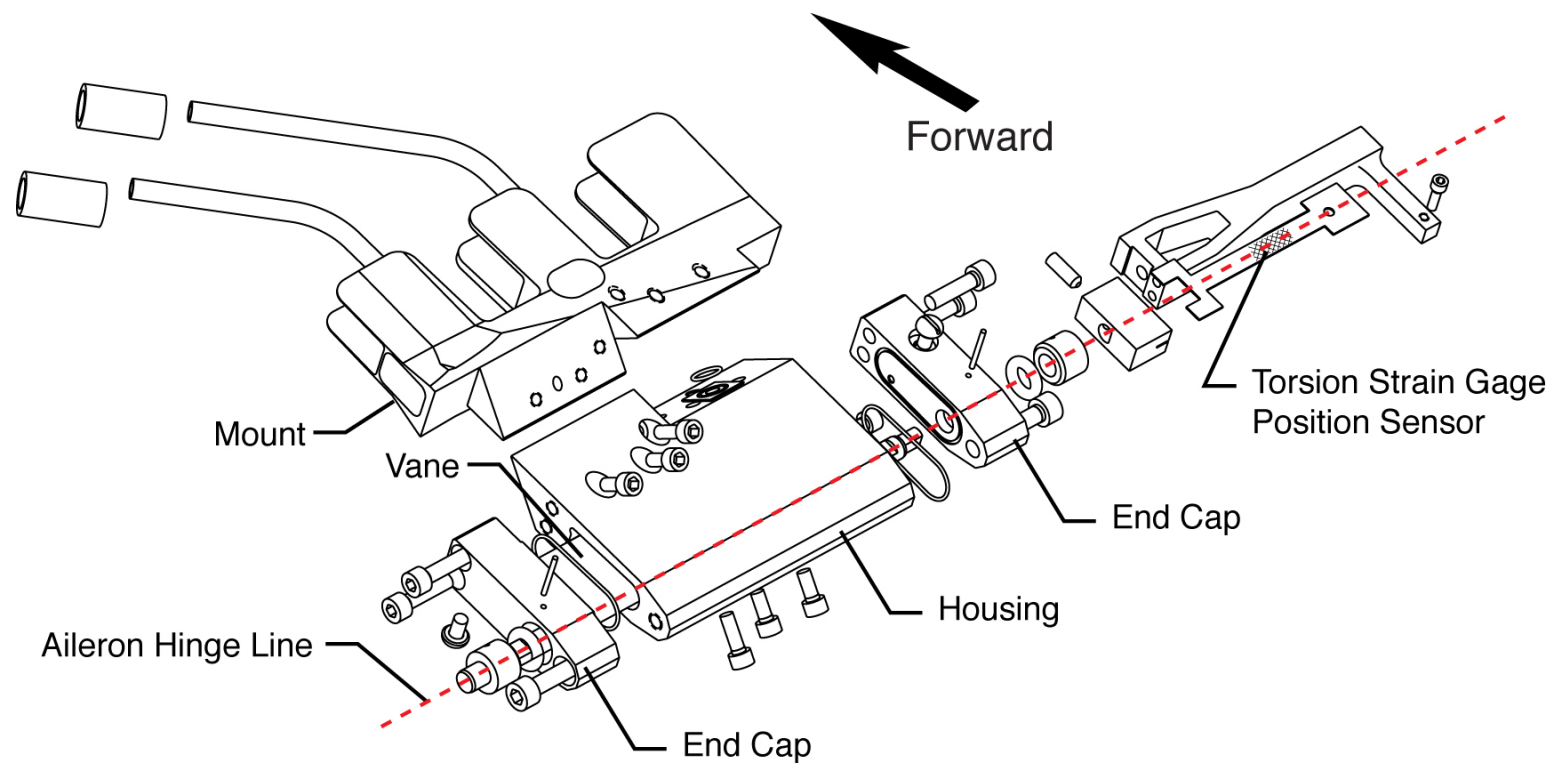

(b) Exploded view of the wing vane-type actuator.

Figure 11. Model actuator details. 
The wing aileron actuator was a more challenging design due to the volume and weight constraints. For the aileron, a NASA Langley designed and fabricated vane-type actuator was developed. Figure 11(b) shows the exploded view of the aileron actuator. The actuator housing was fabricated from VascoMax 300 CVM, an 18\% nickel alloy steel having superior toughness and ductility at yield strength levels up to 300 ksi. This high strength material was required due to the thin walls of the housing (to minimize weight) and the high hydraulic pressures needed to produce the power and responsiveness required for the aileron. The actuator endcaps were fabricated from 15-5 stainless steel and the actuator vane from PH 13-8 Mo stainless steel and cast in Baytec $\AA$ MS-092 polyurethane elastomer. The process of casting of the vane was very challenging and took months of parametric variation in temperature, catalyst concentration, and timing of various process steps to produce a vane suitable for use in the actuator.

\section{III.F. Engines}

The engine nacelles for this model consisted of two separate parts. The engine inlet is rigidly mounted to the wing and the engine nozzle is mounted to a flexible beam that simulates the pylon of the TCA configuration. The front of the inlet has a circular cross-section and transitions to a square cross-section at the aft end of the nozzle. Figure 12(a) contains sketches of the inlet and nozzle of the outboard engine and the shape of various sections along both. Provisions for changing the engine mass were built into the engine nacelles by the inclusion of 10 hollow cylindrical tubes distributed around the perimeter of the flow-through nozzle into which tungsten rods may be placed. Figure 12(b) illustrates the distribution of these tubes. The use of tungsten rods allowed varying engine mass by a factor of 2.5 , which had a significant influence on engine frequency and, ultimately, on the model flutter condition.

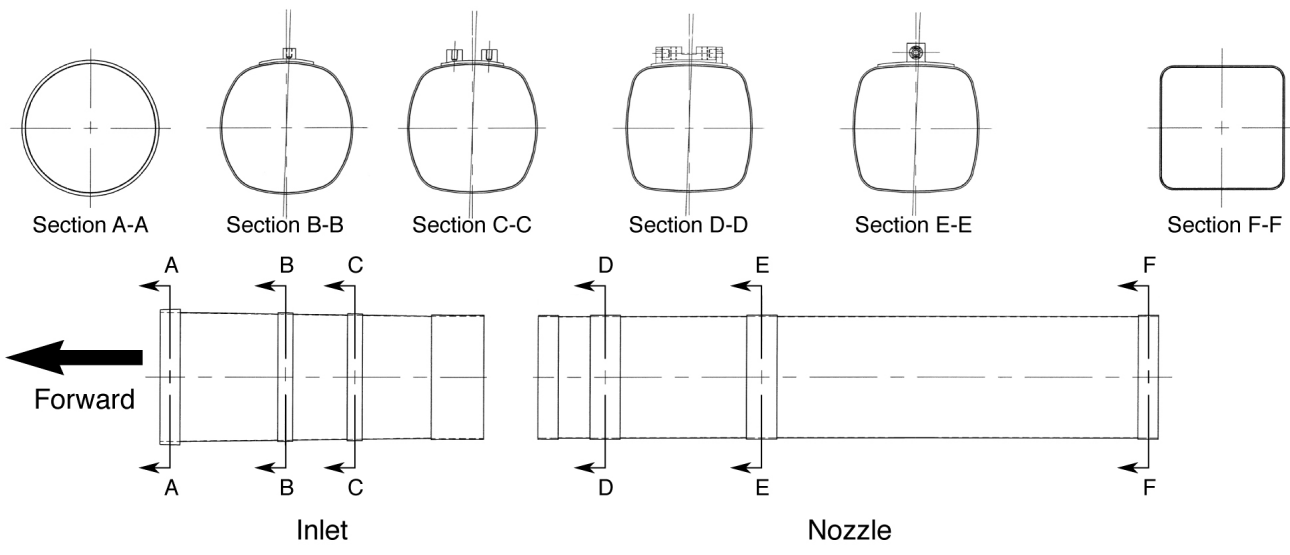

(a) Outboard engine nacelle section details.

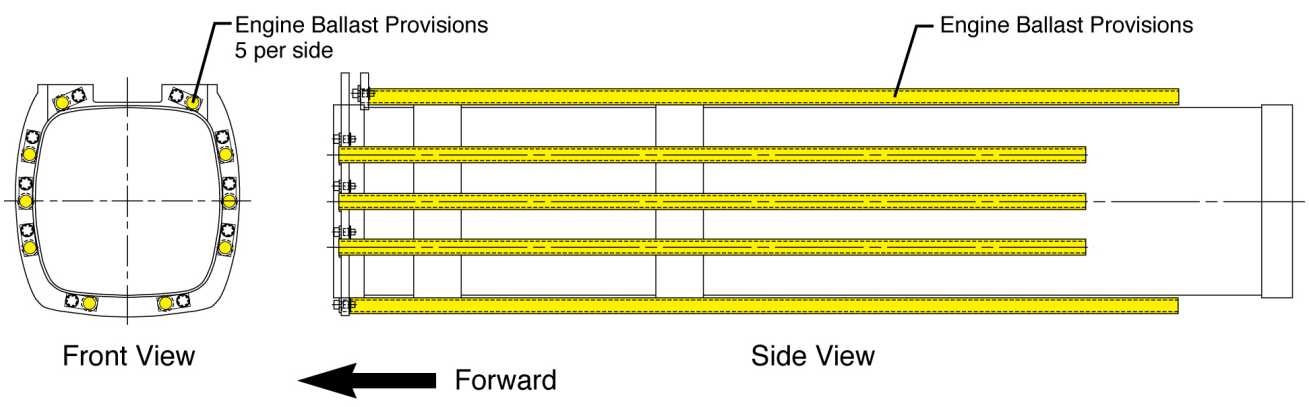

(b) Engine nozzle ballast details.

Figure 12. Engine nacelle details.

Determining the stiffness of the engine pylons was not trivial because the selection of what components belonged with the engine or pylon had an impact on the overall pylon stiffness. Design of the pylon beam began by defining the bending and torsion stiffness for the TCA full-scale model. These stiffnesses were then converted to model scale and appropriate beam/flange dimensions were defined to match the bending and torsion characteristics. The original approach was to match the longitudinal (pitch) mode, with the 
assumption that the lateral modes had minimal impact on flutter. The original pylon beam design had a full flange all the way to the root of the beam. However, in order for the beam to fit within the rear spar attachment, it was necessary to trim the flange near the root. It was expected that this would adversely affect the lateral stiffness, but was deemed appropriate based on the assumption previously mentioned. Three pylon beam concepts were developed and all three had a good correlation with pitch and torsion modes of the TCA pylon, but varied significantly in the lateral stiffness. From this variation, a root flange dimension could be surmised which would match the TCA pylon lateral stiffness and still remain within the allowable space for the rear spar attachment. Figure 13 shows the final nominal pylon design and the tapering of the flange at the root. A reduced stiffness pylon was also designed and fabricated, which turned out to be the size used for essentially all of the wind tunnel testing of the model, along with the 2.5 times heavier engines. The combination of the reduced pylon stiffness and 2.5 times heavier engines resulted in flutter at the lowest tunnel dynamic pressures and model frequencies.

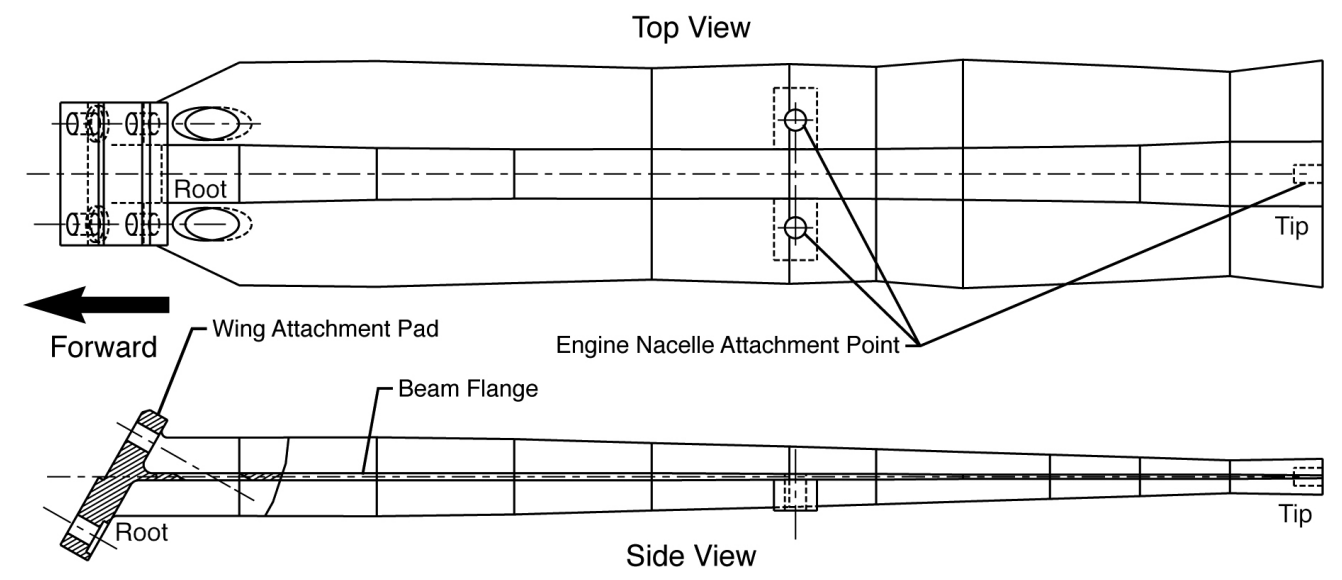

Figure 13. Nominal-stiffness, inboard-nacelle pylon beam.

The TCA engine nacelles and pylons were very detailed and complex. The design of the wind-tunnel model nacelles and engine pylons simplified the mechanisms and aerodynamic shape of the TCA, yet matched the TCA dynamic characteristics. The TCA had engine protrusions through the wing upper surface, but the blending/intersection of these surfaces caused modeling challenges for computational fluid dynamic analysis and some aero-performance analysis had been conducted without this detail (no protrusion of engine through upper wing). From the aft wing extension covering the engine pylons, the wing loft was kept intact by using an aft-extension of the wing lower surface to shave off part of the nacelle geometry. This simplified the aerodynamic shape and design of the model and allowed the nacelles to be easily detached from the wing for possible clean wing testing. Figure 14 shows a picture of the engine pylons installed under the aft wing extension which was part of the TCA engine nacelle.

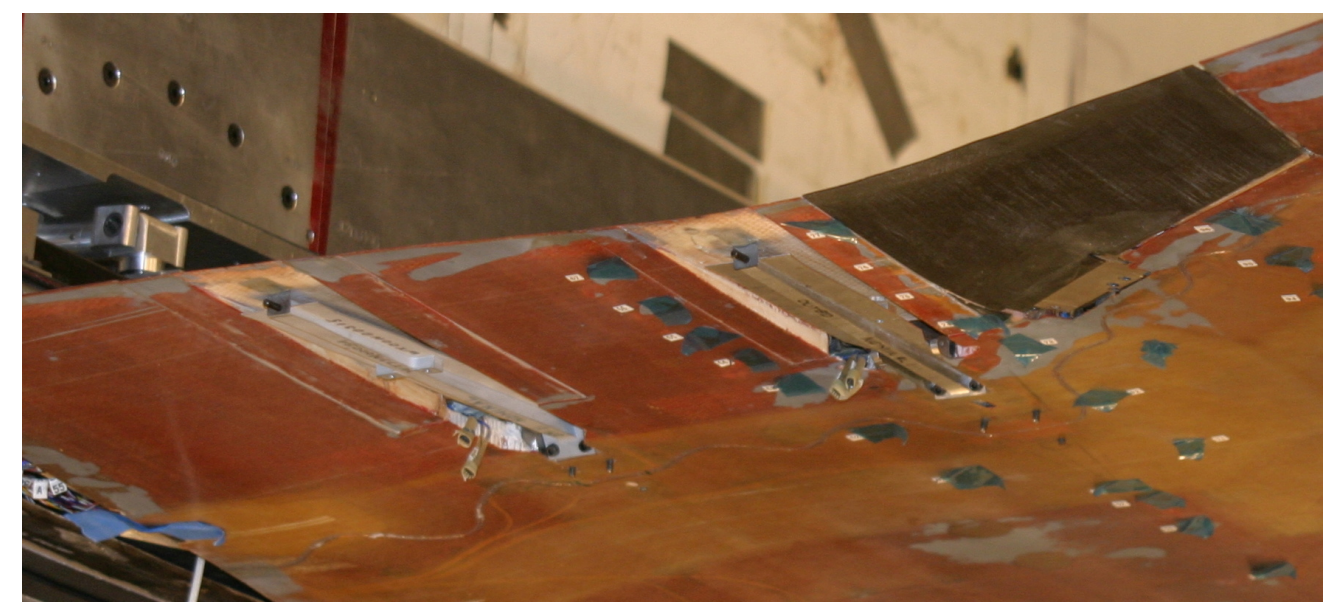

Figure 14. Photo of engine pylons installed beneath aft wing extensions. 


\section{Characterization Tests}

Tests were conducted on the model and its subcomponents during the design and fabrication process to provide data to correlate with analytical results. This allowed the analytical model to be tuned to better simulate the physical model. These tests ranged from simple instrumentation calibrations such as actuator position sensors, to ground vibration tests of the fully assembled model installed in the wind tunnel. This section will focus on a few of the more interesting tests and their results, such as the ground vibration tests, geometry, and stiffness measurements, the wing proof loading, and the fuselage beam characterization.

Prior to wind-tunnel testing the model, extensive modal analysis surveys, or ground vibration tests (GVT), were conducted to characterize the model and monitor its overall dynamic health before and after each of the four tunnel entries. The set up of the GVTs involved the use of a shaker attached at the wing tip which provided an 8-second burst random excitation in the vertical direction. The GVT was typically performed using 14 to 15 roving accelerometers placed at 97 locations on the wing, engines, flexible fuselage beam, and rigid c-channel beam. Several software packages were used to acquire and synthesize the modal data, each yielding similar results with varying levels of effort. In conducting these tests, several lessons were learned that improved the accuracy of the results. Early GVTs suggested that measurement noise had a significant impact on the measured mode shapes. Increasing the amplitude of the driving force excitation reduced the measurement noise. While this improved the modeshape data, it did not satisfactorily resolve the issue. Higher sensitivity $(100 \mathrm{mV} / \mathrm{g}$ versus $10 \mathrm{mV} / \mathrm{g})$ accelerometers were found to greatly improve the measurement noise. Frequency and damping data from the last wind-tunnel entry is give in Table 3 for the first six measured modes. The corresponding measured mode shapes are shown in figure 15. For the most part, frequencies compare well across the board with some variations in damping.

Table 3. Measured damping and frequency (Hz) summary for the fourth wind-tunnel test entry.

\begin{tabular}{|c|c|c|c|c|c|c|}
\hline \multirow{2}{*}{ Mode } & \multicolumn{2}{|c|}{ Pre-Test in Lab } & \multicolumn{2}{c|}{ Pre-Test in Tunnel } & \multicolumn{2}{c|}{ Post-Test in Tunnel } \\
\cline { 2 - 7 } & Frequency & Damping & Frequency & Damping & Frequency & Damping \\
\hline 1 & 6.395 & 3.547 & 6.375 & 5.465 & 6.249 & 3.909 \\
2 & 8.089 & 2.285 & 7.935 & 2.227 & 7.838 & 1.795 \\
3 & 10.323 & 3.518 & 10.312 & 2.616 & 10.059 & 2.889 \\
4 & 11.635 & 3.745 & - & - & 11.781 & 10.903 \\
5 & 12.528 & 1.437 & 12.585 & 2.130 & 12.384 & 3.224 \\
6 & 16.571 & 6.443 & 15.066 & 4.185 & 15.603 & 14.157 \\
\hline
\end{tabular}

Geometric, mass, and static and dynamic structural properties of the wing were measured to ensure analytical results simulated the physical model characteristics. While some measurements were easily conducted, a few property measurements required more specialized efforts. Due to the flexibility of the wing and fuselage beam, a non-contact measurement capability was required for measuring the geometry of the model. The geometry was measured using a three-dimensional laser scanner system that is portable, highly accurate, and provides fast data acquisition. It can obtain accuracies up to \pm 0.002 inches (depending on the range, scan speeds, and type of material scanned) and has a range between 6-80 feet. The geometry of the wing alone, each control surface, and the fully assembled configuration were each measured separately. Almost one million location points were measured, with a higher density of points acquired on the wing and control surfaces. The highest densities of measurement points were on the leading and trailing edges of the wing and control surfaces. The measured geometries were correlated with design geometries to quantify the accuracy of the physical model. Overall, the measured points agreed with design geometry, with the most notable discrepancies of a 0.1-inch step due to the attachment bracket of the fuselage fairing to the aluminum back plate, and a roughly 0.2-inch gap between the wing and fuselage. Neither discrepancy was modeled in the design geometry. The measured geometry validated the design geometry, which was subsequently used to generate the grids for computational fluid dynamic analyses.

\section{IV.A. Wing Properties}

Wing stiffness was measured by applying point loads along the front and rear spars of the outboard wing and measuring the wing deflection using a video model deformation (VMD) system. The measured bending 


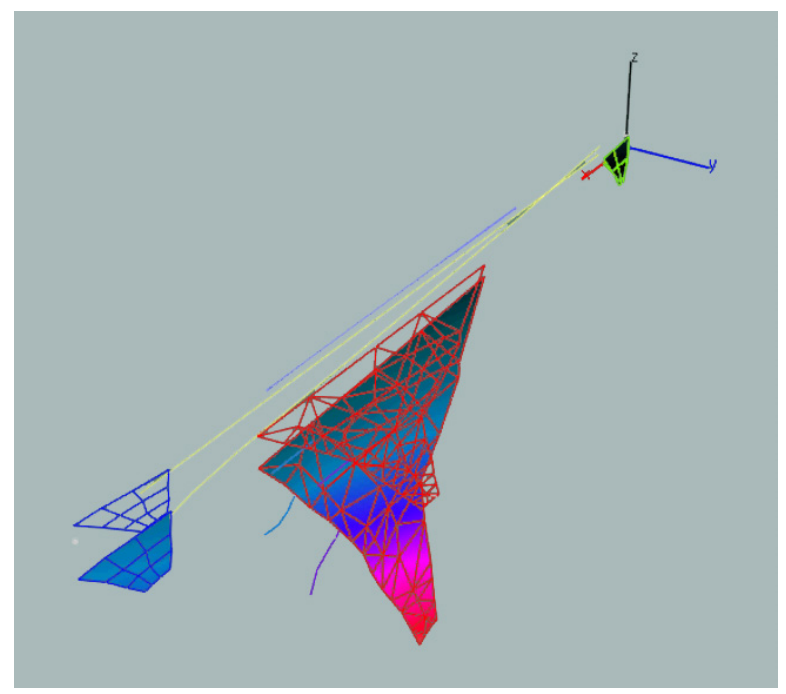

(a) Fuselage pitch about forward nodal mount $-6.249 \mathrm{~Hz}$.

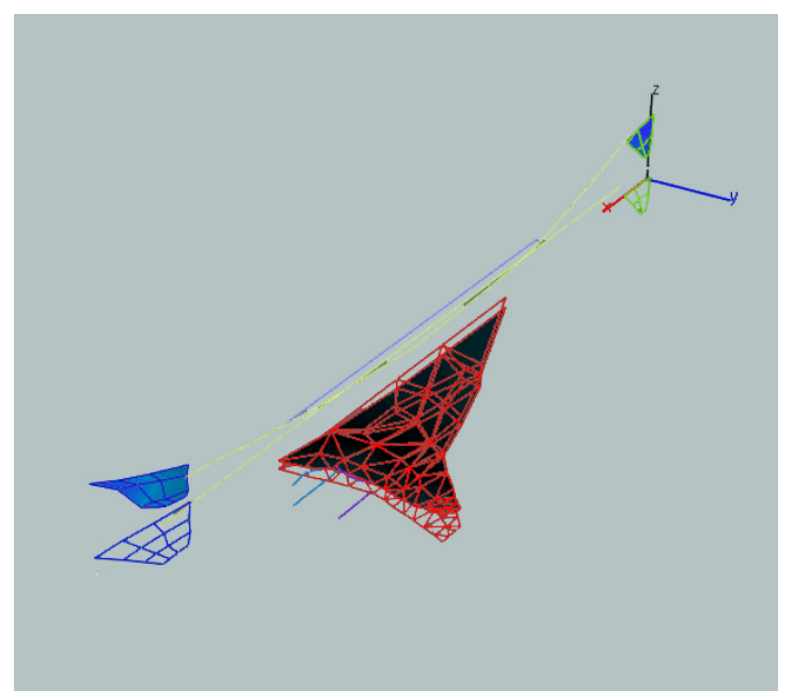

(c) Fuselage bending - $10.059 \mathrm{~Hz}$.

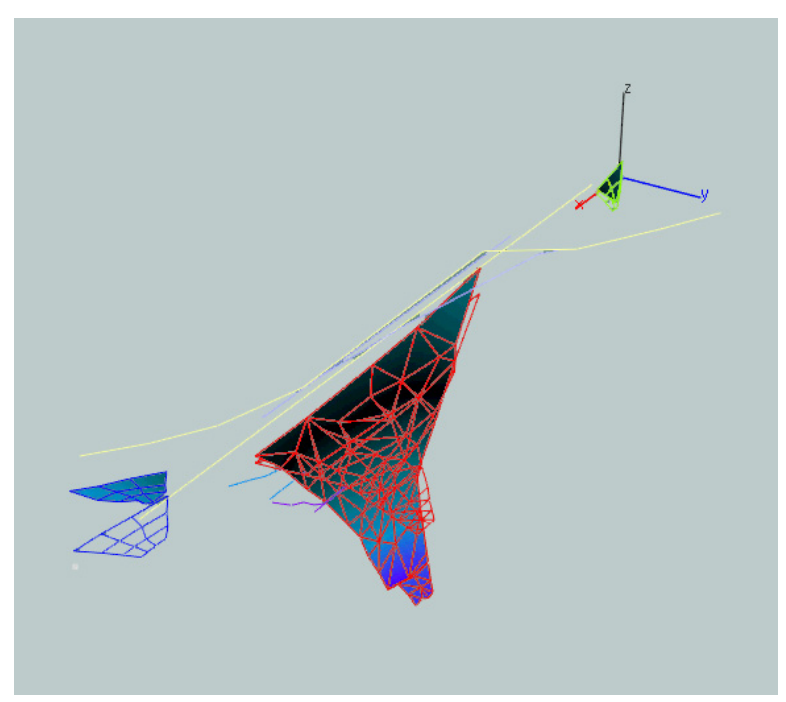

(e) Fuselage and engines lateral - $12.384 \mathrm{~Hz}$.

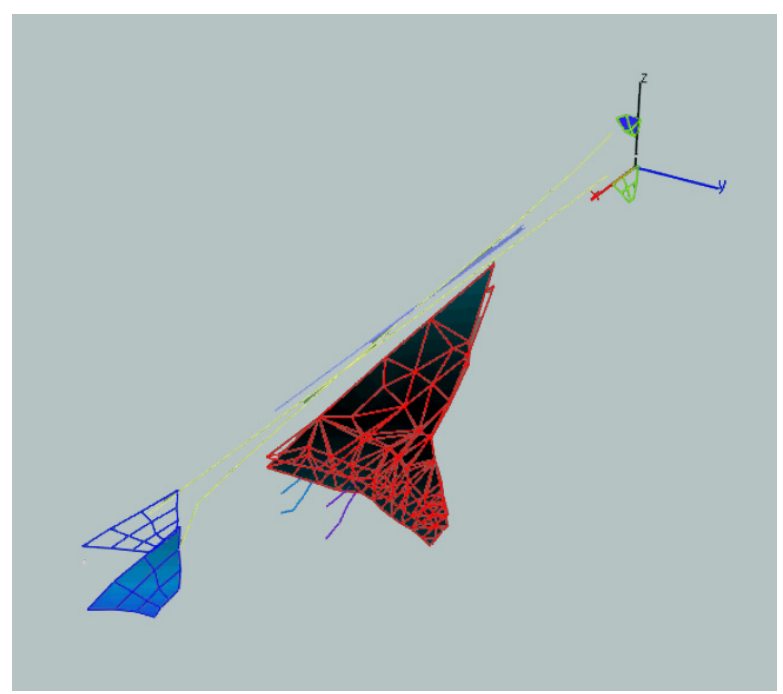

(b) Fuselage pitch about loads balance $-7.838 \mathrm{~Hz}$.

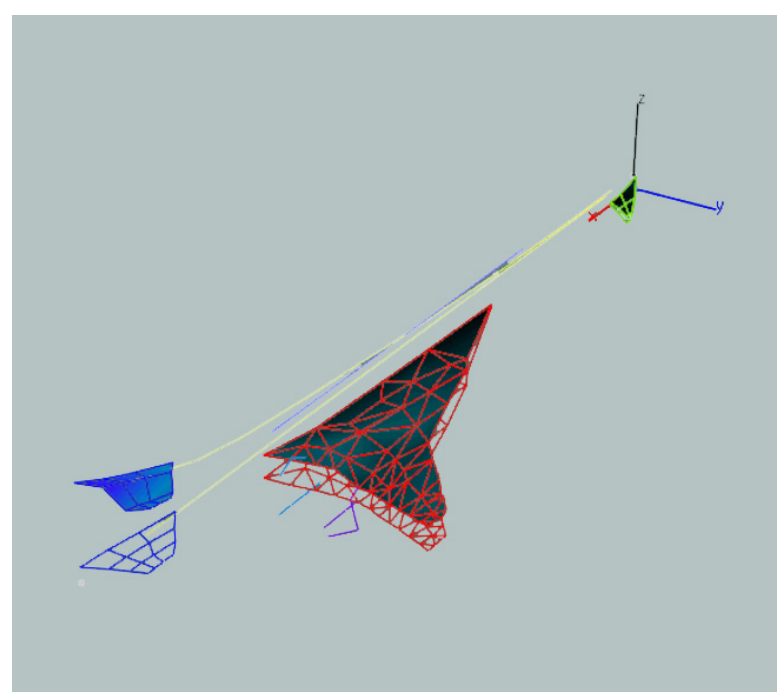

(d) Wing bending - $11.781 \mathrm{~Hz}$.

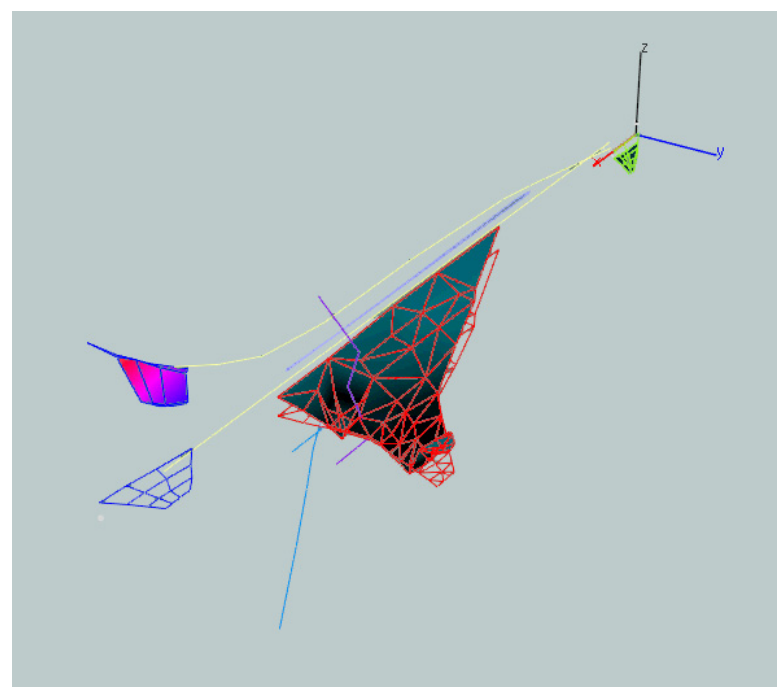

(f) Engines anti-symmetric $-15.603 \mathrm{~Hz}$.

Figure 15. First six measured modeshapes from final GVT. 
deflection results are presented in figure 16. Figure 16(a) contains contours of constant deflection for a 1-pound down load applied on the aft spar three inches inboard from the wing tip; figure 16(b) contains deflection contours for the simultaneous application of a 1-pound up load on the front spar and 1-pound down load on the aft spar, both three inches inboard from the wing tip. These results showed the physical model was stiffer than the scaled analytical model in both bending and torsion. The analytical model was determined to be roughly $35 \%$ softer, so the wing skin thicknesses and fiberglass modulus were modified until the measured wing deflections matched.

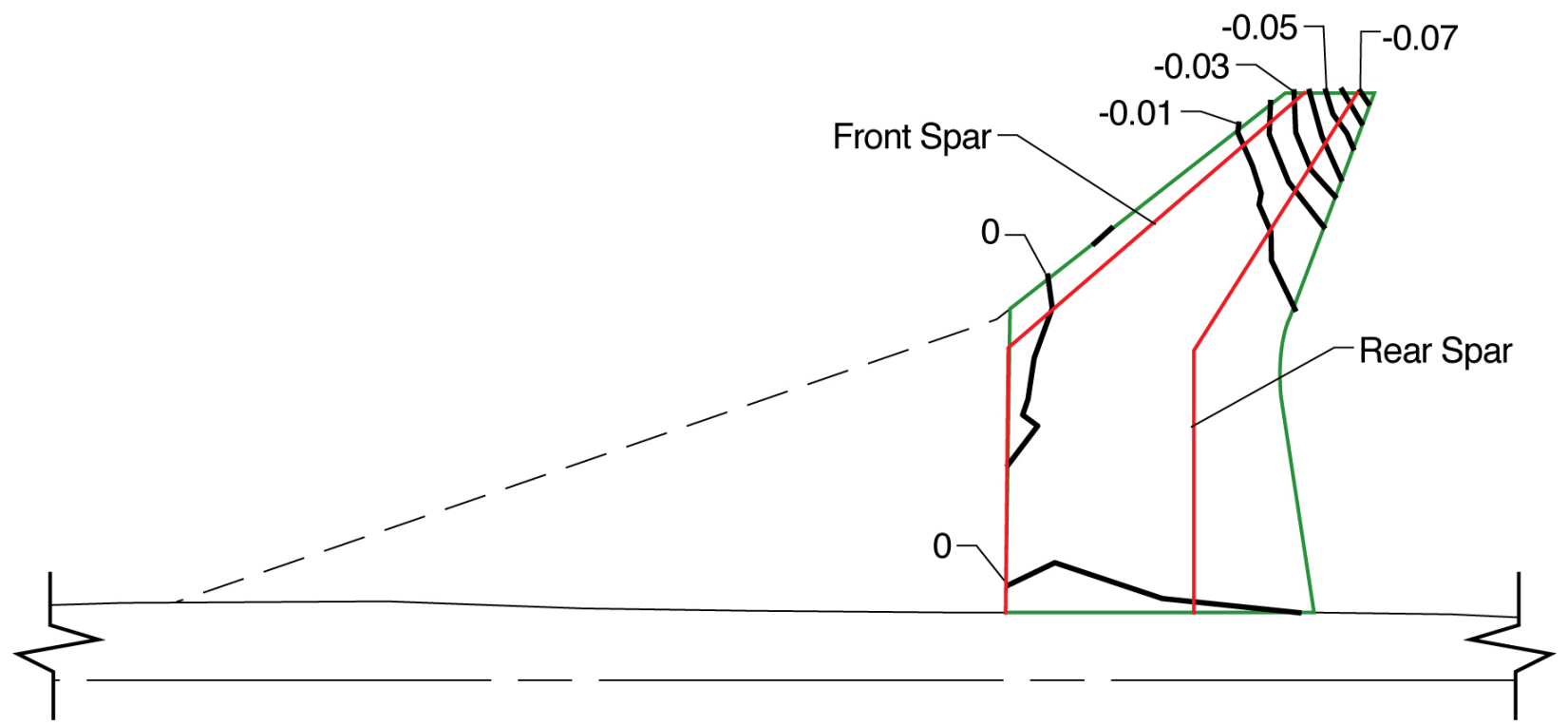

(a) One-pound force applied on rear spar three inches inboard from wing tip.

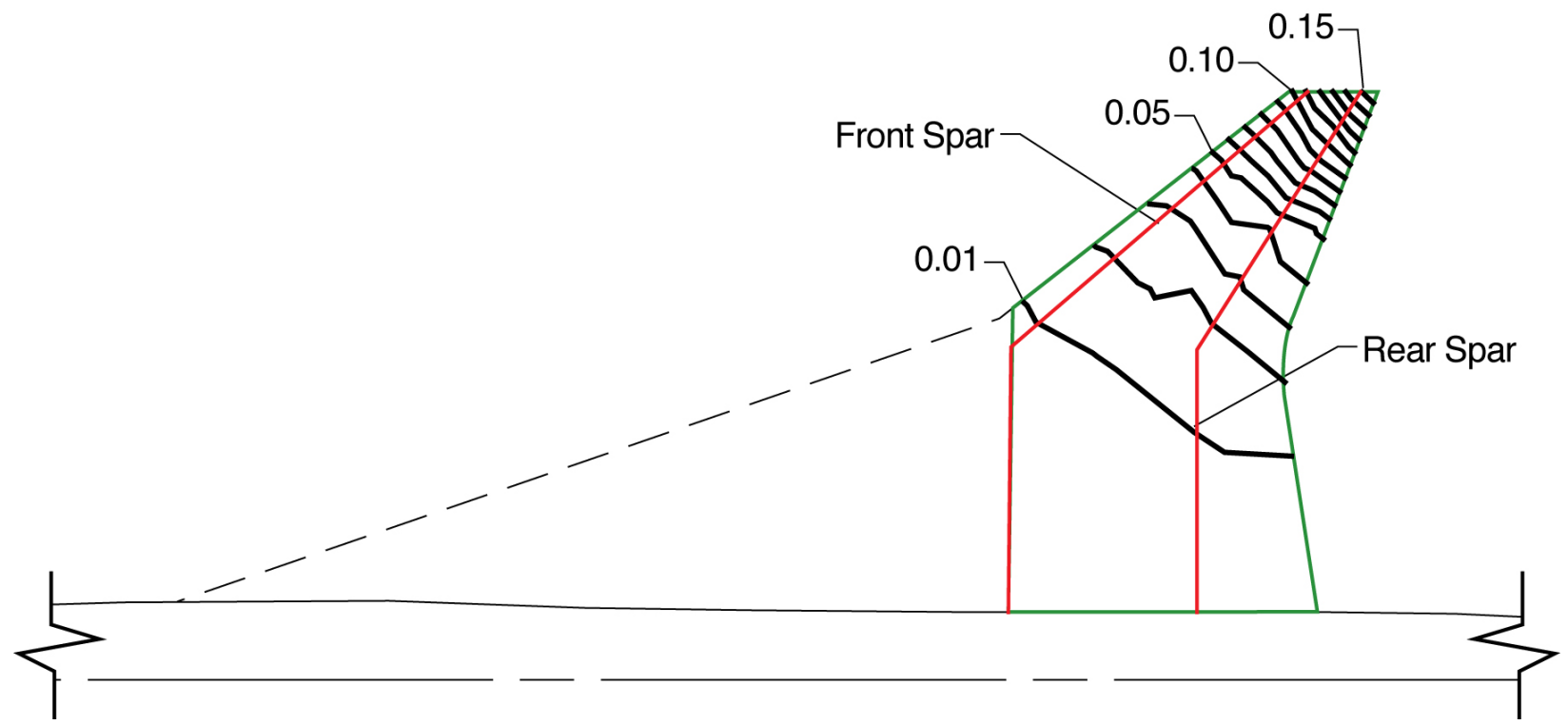

(b) Simultaneous application of a one-pound up load on the front spar and a one-pound down load on the rear spar, both three inches inboard from the wing tip.

Figure 16. Contours of constant deflection for applied loads near wing tip. Contour interval $=0.01$ inches.

One of the more critical tests conducted on the wing was the proof loading test. The wing was to be loaded to two times the expected maximum design load. The maximum design load was defined by a $4 \mathrm{~g}$ pullup maneuver which resulted in a lift load of $353 \mathrm{lbs}$ and a rolling moment of 4097 in-lbs. During the proof loading test, the model failed before achieving the design load. The failure occurred at the Forward Fuselage Attachment Assembly (see figure 9), in the upper roll constraint assembly arm. The arm components are connected through a 5/8-inch diameter pivot flexure with a rated shear capacity of 625 lbs. The model was 


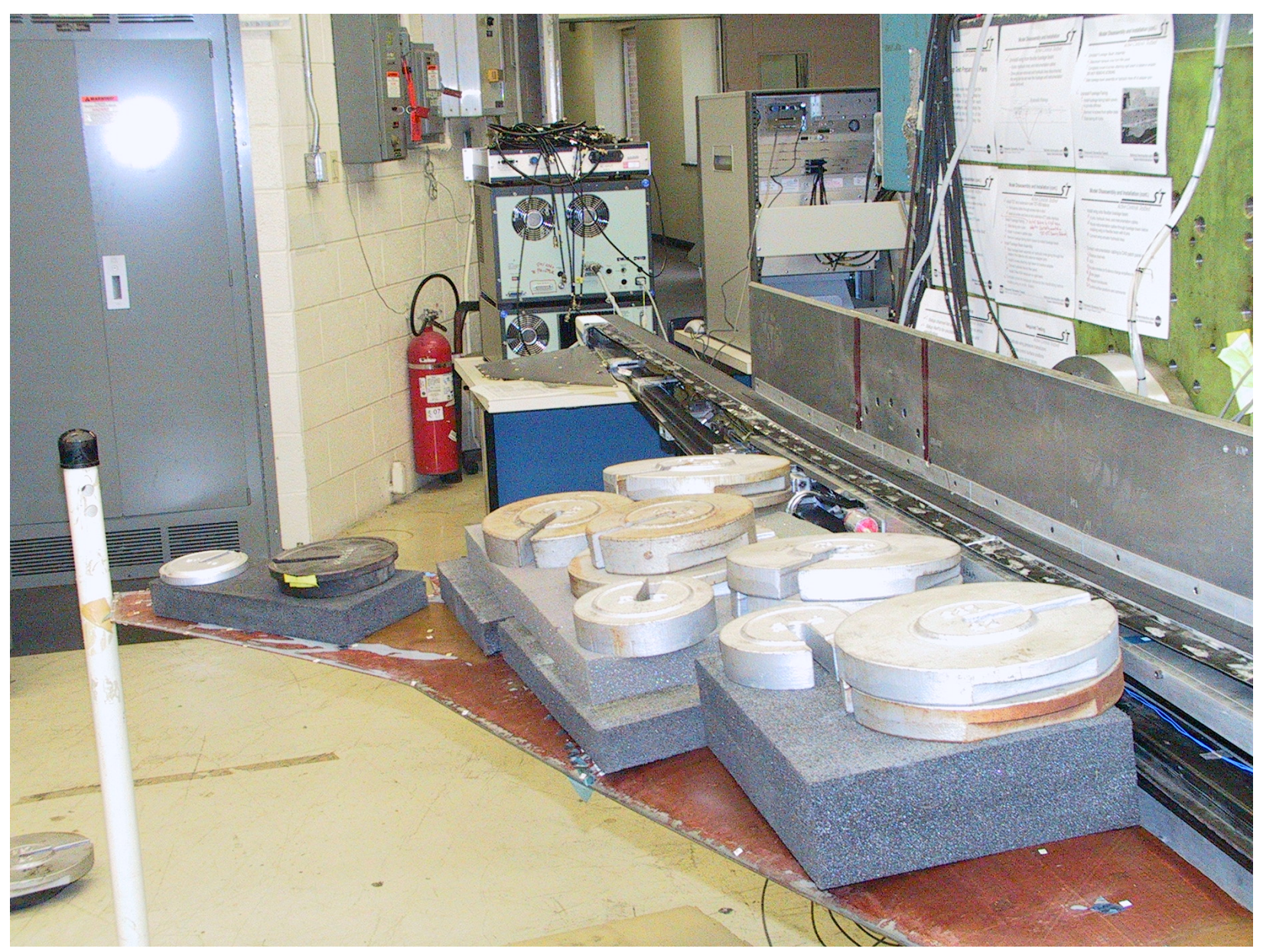

Figure 17. Photograph of wing proof loading.

able to withstand a load of $330 \mathrm{lbs}$ and a rolling moment of 4000 in-lbs before failure. Figure 17 is a photo showing the wing loaded just prior to the failure load being applied. The failure point was analyzed and post test examination of the loading showed the test results agreed with the analysis. Assuming the load was carried equally by the Forward and Aft Fuselage Attachment Assemblies and the moment is about the center of the flexible fuselage cross-section, then the upper and lower 5/8-inch diameter pivot flexures equally share the load. This computes to a shear load on the upper pivot flexure of 2000 in-lbs divided by two flexures divided by the distance from the center of the pivot flexures to the center of the flexible beam (1.6 inches) which equates to $625 \mathrm{lbs}$, the rated shear capacity of the pivot flexure. From these results, the model load limits were set to $165 \mathrm{lbs}$ in normal force and 2000 in-lbs in rolling moment, which is for a factor of safety of two on the measured load limits. This load limit restricted the allowable angle of attacks during static performance tests, but did not have a significant impact on the flutter and dynamic tests conducted in the wind tunnel.

\section{IV.B. Fuselage Beam Properties}

Prior to assembly of the flexible fuselage beam, sections of the beam were tested to determine their static and dynamic structural properties. These results were used to correlate with the analytical model. However, once the beam was assembled, the static and dynamic properties of the assembled flexible beam installed in the rigid c-channel beam with the nodal mounts (figure 9) did not correlate well with the analytical model. The stiffness of the fully assembled flexible fuselage beam was measured by applying moments at three locations (the RCV shaft, the second downstream wing attachment point, and the horizontal tail shaft) separately and measuring the angle of deflection along the beam using a calibrated angle measurement system. Figure 18 
contains a photograph of the test setup in the lab for a moment applied at the second wing attachment point. To best simulate a cantilevered boundary condition for facilitating analytical comparisons with the measured data, deflections for the forward section of flexible beam were measured with the forward nodal mount locked and deflections for the aft section of the flexible beam were measured with the aft nodal mount locked. The stiffness of the fuselage beam section between the nodal mounts was measured in four configurations due to the uncertainty of the stiffness contributions of the nodal mounts and attachment points, which were not removable. The four configurations consisted of various combinations of the forward and aft nodal mounts in their locked and unlocked states. From the measured stiffness data and GVT of the assembled flexible beam, the analytical model was tuned by adjusting the sectional modulus of the beam to better match the static and dynamic characteristics of the physical wind-tunnel model.

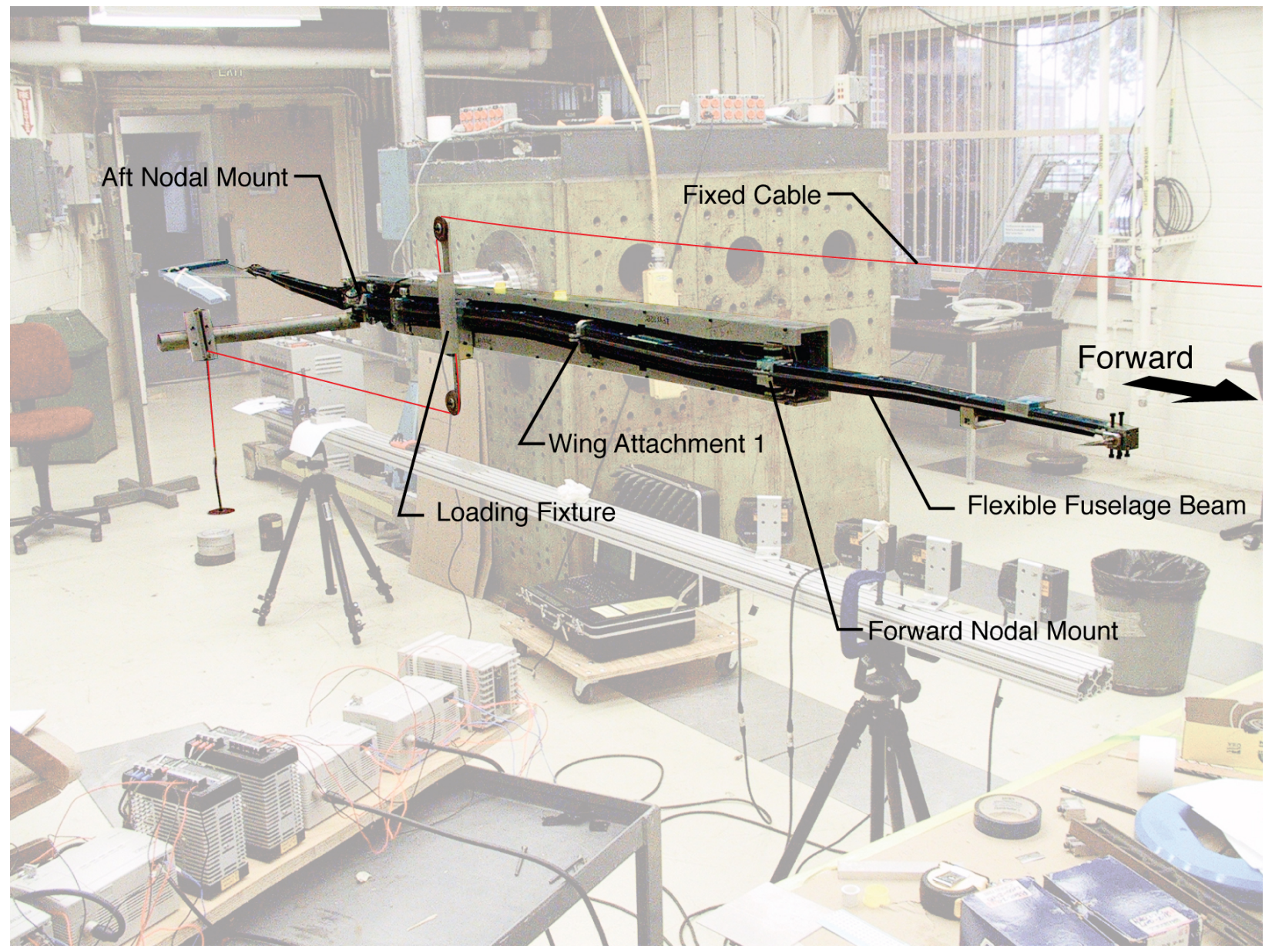

Figure 18. Photograph of the flexible fuselage beam stiffness testing.

Figure 19 shows the results from tuning the analytical model to match the measured deflections for the forward, mid, and aft sections of the fuselage. For the forward and aft sections of the fuselage, the measurements and analysis were done with the nodal mounts locked. This simulated a cantilevered condition as seen by the small deflections near the nodal mount fuselage stations of 51 and 135 . A bending moment was applied using the setup shown in figure 18 at the forward tip of the beam for the forward section and at the aft tip of the beam for the aft section. For the fuselage section between the nodal mounts, the data presented is for the nodal mounts unlocked and the moment applied at Wing Attachment 2, as shown in figure 18. 


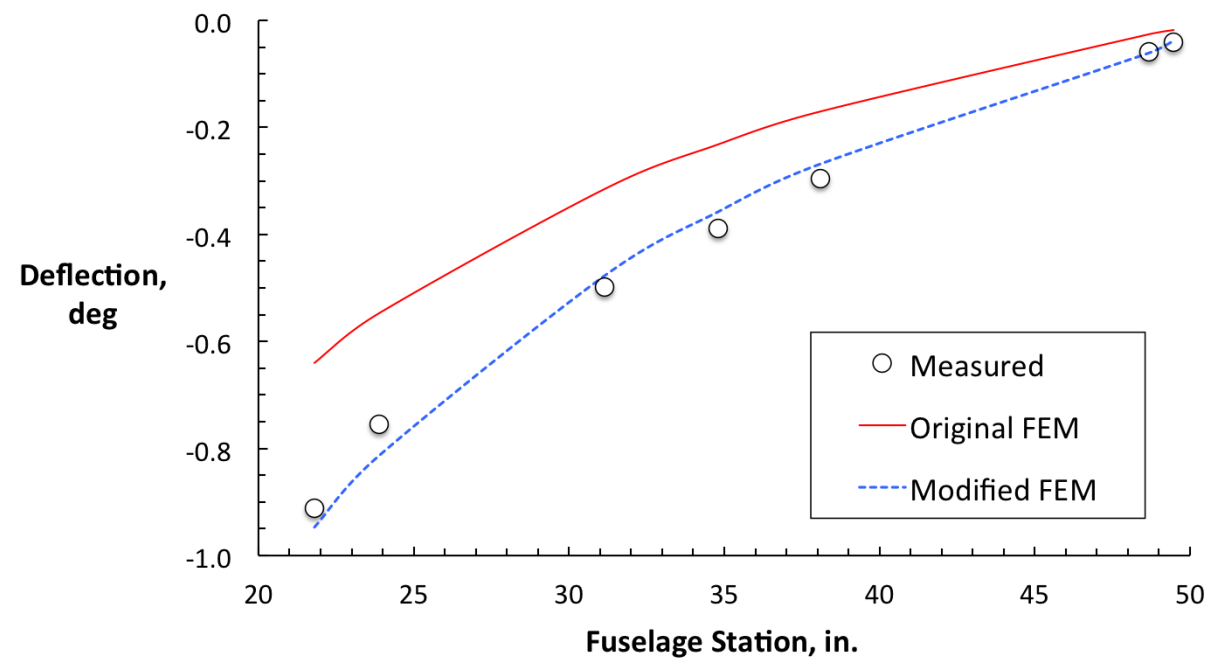

(a) Forward fuselage.

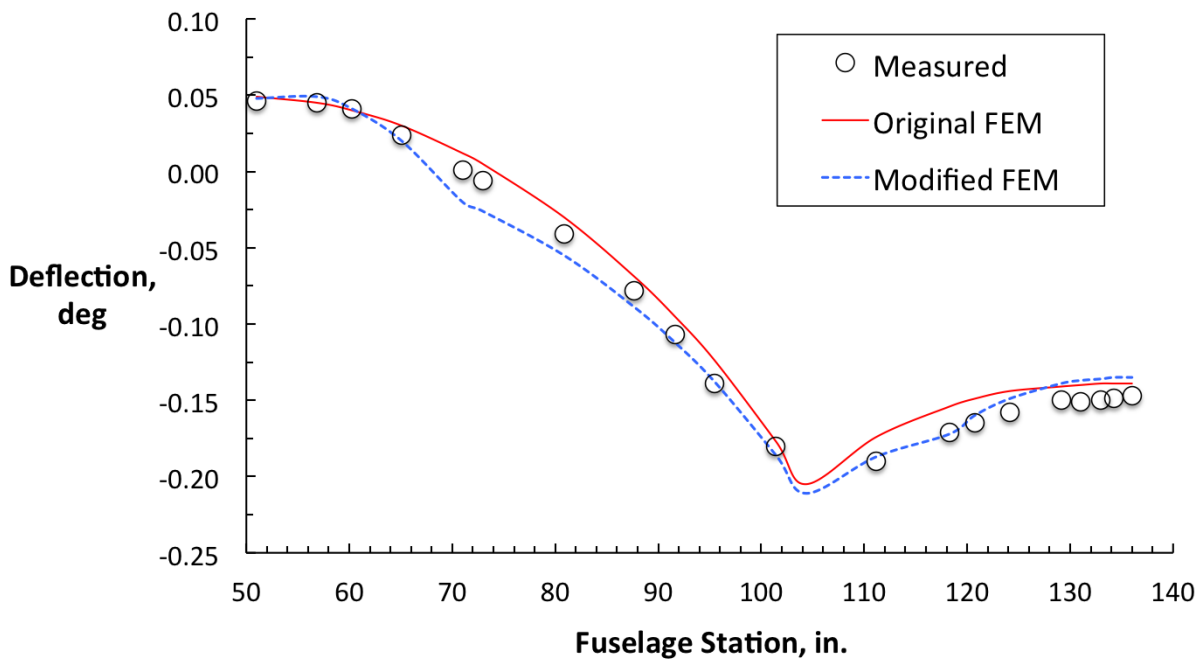

(b) Mid fuselage.

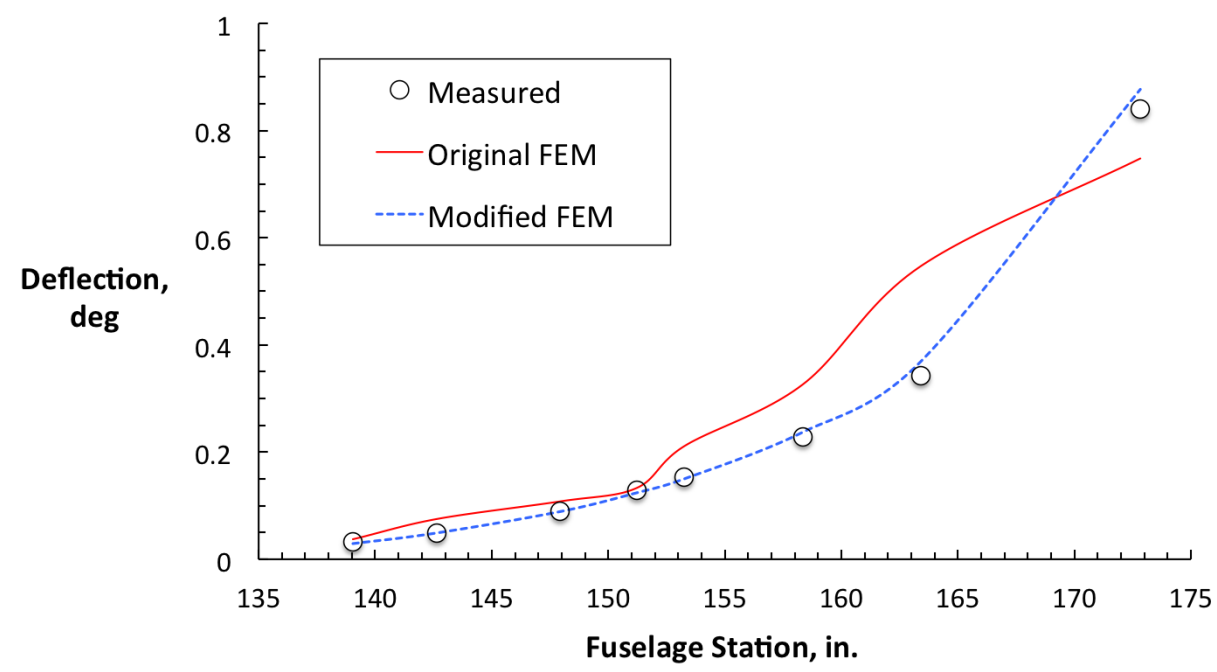

(c) Aft fuselage.

Figure 19. Comparison of original and modified analytical model fuselage deflections with measured fuselage deflections. 


\section{Concluding Remarks}

A brief summary of the more challenging issues faced in the design and characterization testing of the $\mathrm{S}^{4} \mathrm{~T}$ wind-tunnel model were presented. The $\mathrm{S}^{4} \mathrm{~T}$ ACT is a very sophisticated aeroelastic semispan wind-tunnel model designed and fabricated at NASA Langley Research Center. There were many challenging issues in creating the physical wind-tunnel model from the information in the TCA FEM. The challenges of scaling and designing of the outboard wing, the creation of an equivalent stiffness beam for the TCA fuselage shell, the development of the aileron actuator, and the determination of the engine mass variations and pylon stiffness distribution were discussed. Numerous tests were conducted on the model and its subcomponents during the design and fabrication process to correlate with analytical results. The more challenging tests and lessons learned from the process of testing and the results of those tests were presented. These tests included the GVT of the full model, the measurement of the model geometry, the proof loading of the wing, and the testing to accurately characterize the static and dynamic properties of the flexible fuselage beam. These are a sample of the challenges encountered in designing and testing a complex aeroelastic model of a supersonic configuration.

\section{References}

${ }^{1}$ McLean, F. E., "Supersonic Cruise Technology," NASA SP-472, 1985.

2 "NASA High Speed Research (HSR) Overview Fact Sheet," April 2008, http://www.nasa.gov/centers/langley/news/ factsheets/HSR-Overview2.html.

3 "High Speed Research: Aeroelasticity Multi-Year Summary Report For Calendar Years 1996-1999," September 1999, Under Contract NAS1-20220.

${ }^{4}$ Kinsella, W. P. and Robinson, P. A., "Field of Dreams," 1989.

5 "NASA Fundamental Aeronautics Program," July 2009, http://www.hq.nasa.gov/office/aero/programs_fap.htm.

6 "Advanced Aeroservoelastic Testing and Data Analysis," AGARD Conference Proceedings 566, Vol. North Atlantic Treaty Organization, November 1995.

${ }^{7}$ Sandford, M. C., Abel, I., and Gray, D. L., "Development and Demonstration of a Flutter- Suppression System Using Active Controls," NASA TR R-450, 1975.

${ }^{8}$ Abel, I., Perry, III, B., and Newsom, J. R., "Comparison of Analytical and Wind-Tunnel Results for Flutter and Gust Response of a Transport Wing with Active Controls," NASA-TP-2010, 1982.

${ }^{9}$ Waszak, M. R., "Robust Multivariable Flutter Suppression for the Benchmark Active Control Technology (BACT) WindTunnel Model," 11th Symposium on Structural Dynamics and Control, Blacksburg, VA, May 1997.

${ }^{10}$ Multiple, "Special Section: Active Flexible Wing," Journal of Aircraft, Vol. 32, No. 1, 1995, pp. 9-76,206-207.

${ }^{11}$ Pendleton, E. W., Bessette, D., Field, P. B., Miller, G. D., and Griffin, K. E., "Active Aeroelastic Wing Flight Research Program Technical Program and Model Analytical Development," Journal of Aircraft, Vol. 37, No. 4, 2000 , pp. 554-561.

${ }^{12}$ Silva, W. A., Keller, D. F., Florance, J. R., Cole, S. R., and Scott, R. C., "Experimental Steady and Unsteady Aerodynamic and Flutter Results for HSCT Semispan Models," 48th AIAA/ASME/ASCE/AHS/ASC Structures, Structural Dynamics, and Materials Conference and Exhibit, Vol. AIAA-2000-1697, Atlanta, GA, April 2000.

${ }^{13}$ Perry, III, B., Silva, W. A., Florance, J. R., Wieseman, C. D., Pototzky, A. S., Sanetrik, M. D., Scott, R. C., Keller, D. F., and Cole, S. R., "Plans and Status of Wind-Tunnel Testing Employing an Aeroservoelastic Semispan Model," 41st AIAA/ASME/ASCE/AHS/ASC Structures, Structural Dynamics, and Materials Conference and Exhibit, Vol. AIAA-20071770, Honolulu, HI, April 2007.

${ }^{14}$ Roughen, K. and Bendiksen, O., "Active Flutter Suppression of the Supersonic Semispan Transport (S4T) Model," 51st AIAA/ASME/ASCE/AHS/ASC Structures, Structural Dynamics, and Materials Conference and Exhibit, Vol. AIAA 2010-2621, Orlando, FL, April 2010.

${ }^{15}$ Moulin, B., Ritz, E., Chen, P. C., Lee, D. H., and Zhang, Z., "CFD-Based Control for Flutter Suppression, Gust Load Alleviation, and Ride Quality Enhancement for the S4T Model," 51st AIAA/ASME/ASCE/AHS/ASC Structures, Structural Dynamics, and Materials Conference and Exhibit, Vol. AIAA-2010-2623, Orlando, FL, April 2010.

${ }^{16}$ Moulin, B., Ritz, E., Florance, J. R., Sanetrik, M. D., and Silva, W. A., "CFD-Based Classic and Robust Aeroservoelastic Control for the SuperSonic SemiSpan Transport Wind-Tunnel Model," AIAA Guidance, Navigation, and Control Conference, Vol. AIAA-2010-7802, Toronto, CA, Aug. 2010.

${ }^{17}$ Silva, W. A., Perry, III, B., Florance, J. R., Sanetrik, M. D., Wieseman, C. D., Stevens, W. L., Funk, C. J., Hur, J., Christhilf, D. M., and Coulson, D. A., "An Overview of Preliminary Computational and Experimental Results for the SemiSpan Super-Sonic Transport (S4T) Wind-Tunnel Model," International Forum of Aeroelasticity and Structural Dynamics, Vol. IFASD-2011-147, Paris, France, June 2011.

${ }^{18}$ Busan, R., "Flutter Model Technology," WL-TR-97-3074, 1997.

${ }^{19}$ Liu, D. D., Sarhaddi, D., Piolenc, F. M., Wasserman, L. S., Roberts, W., Donham, R. E., Watts, G. A., and Peloubet, Jr., R. P., "Flutter Prevention Handbook: A Preliminary Collection," WL-TR-96-3111, 1997.

${ }^{20}$ Timoshenko, S. and Gere, J. M., Mechanics of Materials, Van Nostrand Reinhold Co., 1972. 